\title{
USO DE PROTETORES E REFRIGERAÇÃO NA CONSERVAÇÃO DA MANGA (Mangifera indica L.) cV. PALMER
}

\author{
MANOEL LUÍZ DE MELO NETO \\ Engenheiro Agrônomo
}

Orientador: Prof. Dr. PEDRO JACOB CHRISTOFFOLETI

Dissertação apresentada à Escola Superior de Agricultura "Luiz de Queiroz", da Universidade de São Paulo, para obtenção do título de Mestre em Agronomia, Área de Concentração: Fitotecnia

PIRACICABA

Estado de São Paulo - Brasil Julho - 1996 
Dados Internacionais de Catalogação na Publicação (CIP) DIVISĀo DE BIBLIOTECA E DOCUMENTAÇĀO - Campus "Luiz de Queiroz"/USP

Melo Neto, Manoel Luiz de

Uso de protetores e refrigeraçăo na conservação da manga (Mangifera indica L.)

cv. Palmer / Manoel Luiz de Melo Neto. - - Piracicaba, 1996.

68 p. : 11 .

Dissertaçăo (mestrado) - - Escola Superior de Agricultura Luiz de Queiroz, 1996.

Bibliografia.

1. Manga - Armazenamento 2. Manga - Conservação pelo frio I. Título

CDD 634.441 


\section{USO DE PROTETORES E REFRIGERAÇÃO NA CONSERVAÇÃO DA MANGA (Mangifera indica L.) cV. PALMER}

\section{MANOEL LUÍZ DE MELO NETO}

Aprovada em: 04 / 09 / 96.

Comissão julgadora:

Prof. Dr. Pedro Jacob Christoffoleti ESALQ/USP

Prof. Dr. Salim Simão ESALQ/USP

Prof. Dr. Ede Cereda UNESP/BOTUCATU

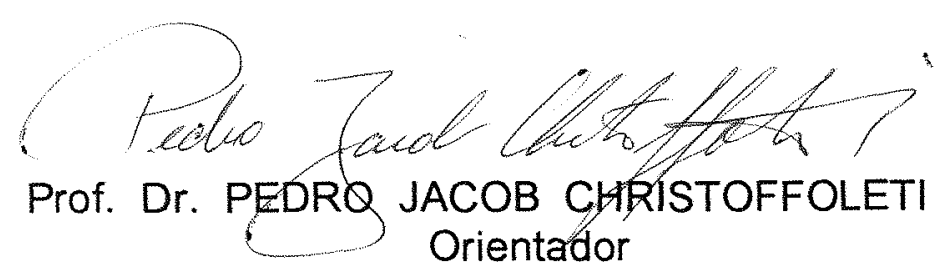


Aos meus pais

e aos meus irmãos,

OFEREÇO.

A minha esposa DIONE MELO e à nossa filha DRIELLY MELO,

DEDICO. 


\section{AGRADECIMENTOS}

Ao Prof. Dr. Pedro Jacob Christoffoleti pela orientação e principalmente pela amizade desenvolvida.

Ao Diretor Geral do ITAL - Campinas/SP, Dr. Nelson José Beraquet.

Ao Pesquisador do ITAL - Campinas/SP, José Maria Monteiro Sigrist pela colaboração, apoio, sugestões prestadas nas análises laboratoriais e durante a elaboração deste trabalho e, principalmente pela amizade.

A Pesquisadora do ITAL - Campinas/SP, Rosa Maria Jercelino Alves pelas sugestões e realização das análises sensoriais e de composição gasosa e, principalmente pela amizade.

À todos os professores do curso de Fitotecnia pela dedicação e conhecimentos transmitidos.

Ao Sr. Sérgio Colombo, produtor de manga, pela concessão das caixas utilizadas no experimento.

Aos fabricantes e representantes dos materiais utilizados neste trabalho.

Aos estagiários, da seção FRUTOTEC - ITAL, Leandro Numata, Daniel Andrade de Siqueira Franco, Luiz Fernando Fracassi e Marcelo Pohlmann pela ajuda, dedicação e amizade.

A Luciana Assis Rodrigues, Técnica de Apoio à Pesquisa Científica e Tecnológica do ITAL, pela ajuda, dedicação e amizade. 
A Quitéria Maria A. de Oliveira, Auxiliar de Apoio à Pesquisa Científica e Tecnológica do ITAL, pela ajuda, dedicação e amizade.

A Carlos Ernesto de Arruda, Agente de Apoio à Pesquisa Científica e Tecnológica do ITAL, pela ajuda, dedicação e amizade.

À Empresa Pernambucana de Pesquisa Agropecuária - IPA, pela oportunidade concedida para realização deste curso.

À Coordenadoria de Aperfeiçoamento de Pessoal de Ensino Superior (CAPES) pelo apoio financeiro e institucional prestado para a realização deste trabalho.

Enfim a todos aqueles que de uma forma ou de outra contribuíram para a realização deste trabalho. 


\section{SUMÁRIO}

Página

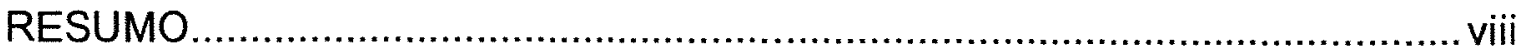

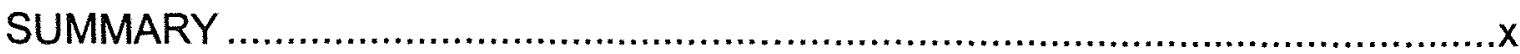

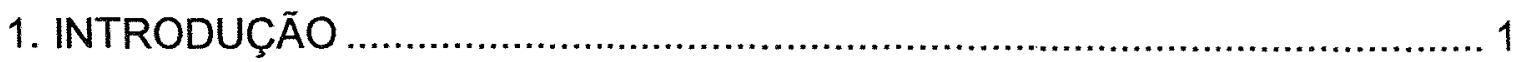

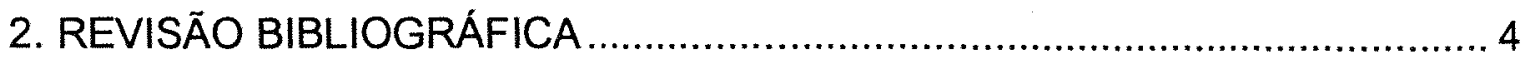

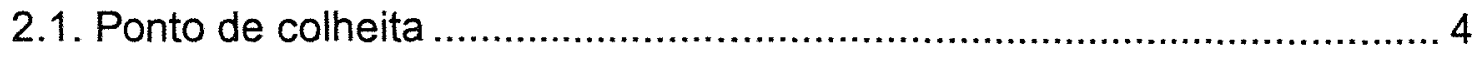

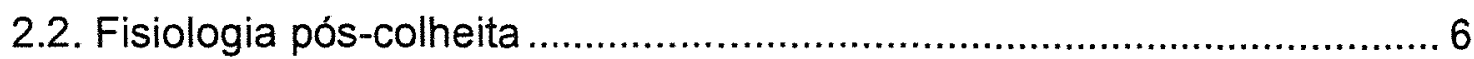

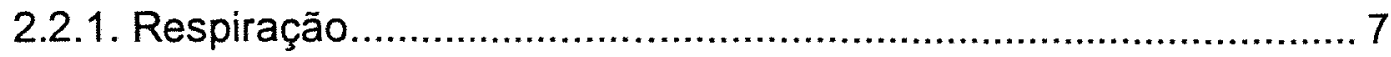

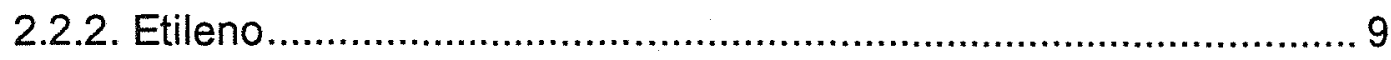

2.2.3. Constituição química ............................................................. 10

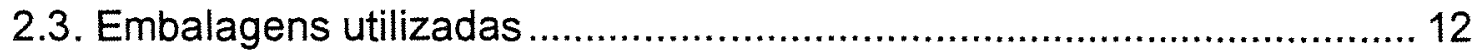

2.4. Conservação pós-colheita .............................................................. 13

2.4.1. Armazenamento sob refrigeração........................................... 13

2.5. Tratamentos de proteção dos frutos com atmosfera modificada (AM) .. 16

2.5.1. Uso de filmes plásticos .......................................................... 16

2.5.2. Uso de ceras e coberturas de superfície .................................. 19

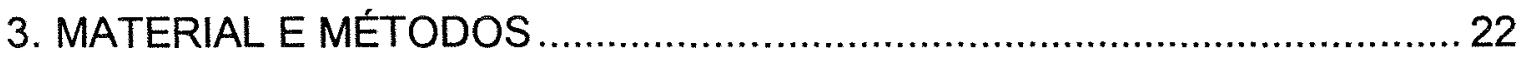

3.1. Origem, colheita e preparo dos frutos ........................................... 22

3.2. Descrição da cultivar ........................................................................ 23

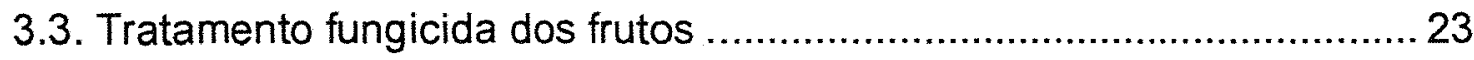

3.4. Filmes plásticos e ceras utilizadas …............................................. 24

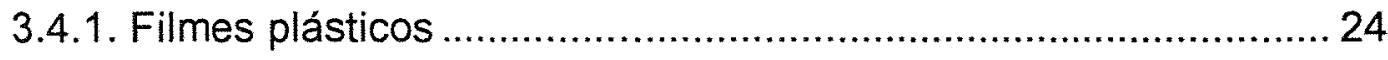

3.4.2. Ceras e recobrimento ........................................................... 24

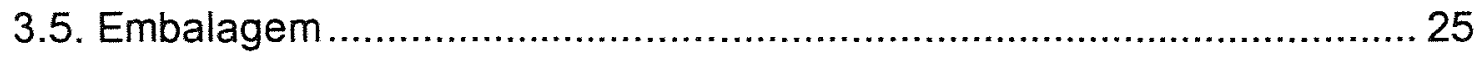

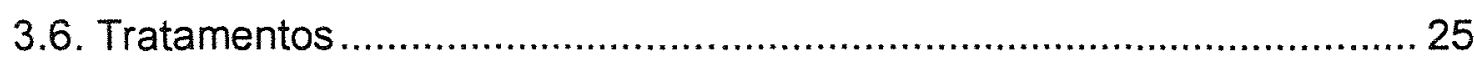

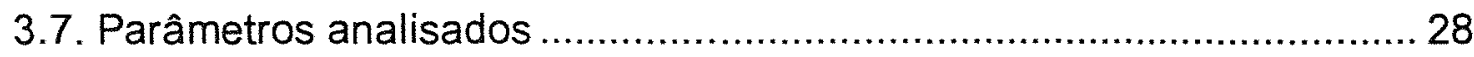

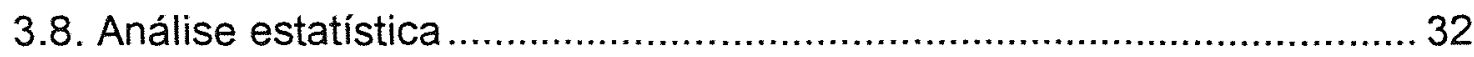


4. RESULTADOS E DISCUSSÃO. 33

4.1. Análise dos parâmetros físicos e químicos das mangas submetidas aos diferentes tratamentos e armazenadas a $12^{\circ} \mathrm{C}$ durante 15,21 e 28 dias, sendo em seguida transferidas para $25^{\circ} \mathrm{C}$ por 7,8 e 6 dias, respectivamente. 33

4.2. Análises sensoriais das mangas embaladas com filmes plásticos, armazenadas por 21 e 28 dias a $12^{\circ} \mathrm{C}$ e após transferência por 8 dias (29 dias) e 6 dias (34 dias) respectivamente, para $25^{\circ} \mathrm{C}$ 48

4.3. Composição gasosa no interior das embalagens 51

5. CONCLUSÕES 54 REFERÊNCIAS BIBLIOGRÁFICAS 55 APÊNDICE 67 


\title{
USO DE PROTETORES E REFRIGERAÇÃO NA CONSERVAÇÃO DA MANGA (Mangifera indica L.) cv. PALMER
}

\author{
Autor: Manoel Luíz de Melo Neto \\ Orientador: Prof. Dr. Pedro Jacob Christoffoleti
}

RESUMO

Mangas da cultivar Palmer foram submetidas a tratamentos com ceras e filmes plásticos, visando a sua conservação e a manutenção das características de qualidade, quando armazenadas sob condições de refrigeração. Os frutos foram colhidos em completo desenvolvimento (maturidade fisiológica), apresentando coloração da casca verde e consistência da polpa dura. Após seleção, quanto ao tamanho e estádio de maturação, objetivando alcançar maior uniformidade do lote, os frutos receberam um tratamento fungicida à base de prochloraz 450g/l CE, diluído na concentração de 1000 ppm, à temperatura de $22 \pm 3^{\circ} \mathrm{C}$, por dois minutos. Os tratamentos foram os seguintes: CONTROLE - as mangas sofreram apenas tratamento fungicida e foram colocadas em embalagem de papelão, o que foi comum para todos os tratamentos; D-955 - as mangas foram embaladas em saco plástico poliolefínico, com espessura da parede simples de $21 \pm 1,68 \mu \mathrm{m} ; \mathrm{PD}-941$ - as mangas foram embaladas em saco plástico poliolefínico, com espessura da parede simples de $20 \pm 0,99 \mu \mathrm{m}$; PP PERF. - as mangas foram embaladas em saco plástico denominado polipropileno perfurado, com espessura da parede simples de $44 \pm 4,62 \mu \mathrm{m}$; CERA A 1:1 - as mangas 
foram pulverizadas com a CERA A (composta de resinas fumáricas de pinus, polímeros e etilenoglicóis) na diluição de 1:1 ( uma parte do produto para uma parte de água); CERA A 1:3 - as mangas foram pulverizadas com a CERA A na diluição de 1:3; este mesmo procedimento foi utilizado para a CERA B 1:1 e 1:3 (composta de uma emulsão de carnaúba aditivada) e o recobrimento REC. 1:1 e 1:3 (composto de resina natural). Após receberem os tratamentos os frutos foram embalados em caixas de papelão, oito frutos/caixa, e imediatamente, condicionadas em câmara frigorífica $\left(12 \pm 1,5^{\circ} \mathrm{C}\right.$ e $85-95 \%$ UR), na quantidade de seis caixas por tratamento. Após 15, 21 e 28 dias foram transferidas para as condições controladas ( $25 \pm 2{ }^{\circ} \mathrm{C}$ e $85-95 \%$ UR), onde permaneceram por mais 7 , 8 e 6 dias, respectivamente, sendo então retiradas para avaliação final da evolução do amadurecimento. O uso de ceras e filmes plásticos não tiveram influência sobre a vida útil dos frutos. Os frutos tratados com filmes plásticos adquiriram sabor fermentado. Os filmes plásticos PD-941 e D-955 retardaram o desenvolvimento dos sólidos solúveis dos frutos, embora isso não tenha refletido no aumento da sua vida útil. O filme plástico PP PERF. não alterou as características de qualidade dos frutos. A composição gasosa no interior da embalagem plástica PD-941, se mostrou mais adequada que a D-955. Os frutos submetidos ao filme plástico D-955 não desenvolveram a cor da casca normalmente. Os tratamentos com proteção de CERA 1:1, com finalidade de conservar os frutos, não foram efetivos. O tratamento REC. 1:1 não foi efetivo na manutenção das características dos frutos. 


\title{
USE OF PROTECTORS AND REFRIGERATION ON MANGO (Mangifera indica L.) cV. PALMER CONSERVATION
}

\author{
Author: Manoel Luiz de Melo Neto \\ Adviser: Prof. Dr. Pedro Jacob Christoffoleti
}

\section{SUMMARY}

Mangoes of cultivar Palmer were submitted to treatments with wax and plastic films, aiming the conservation and maintenance of fruit quality, when stored under refrigeration conditions. The fruits were harvested after complete development (physiological maturity), presenting green skin color and hard pulp. After selection for size and maturity stage, in order to get uniformity of the fruits, they received a treatment fungicide of prochloraz $450 \mathrm{~g} / \mathrm{CE}$, at $1000 \mathrm{ppm}$, at temperature of $22 \pm 3^{\circ} \mathrm{C}$, for two minutes. The treatments were: $\mathrm{CONTROL}$ - the mangoes were only treated with fungicide and packed in a paper box, this packaging was made for all treatments; D-955 - mangoes were packed in polyolefinic plastic bag, thickness of $21 \pm 1.68 \mu \mathrm{m}$; PD-941 - mangoes were packed in polyiolefinic plastic bag, thickness of $20 \pm 0.99 \mu \mathrm{m}$; PP PERF. mangoes were packed in polypropylene plastic bag with small holes in it, thickness of $44 \pm 4.62 \mu \mathrm{m}$; WAX A 1:1 - mangoes were sprayed with wax $A$ in a dilution of $1: 1$ (wax:water); WAX A 1:3 - mangoes were sprayed with wax $A$ in a dilution 1:3; the same procedure was used for WAX B 1:1 and 1:3 and REC. 1:1 and 1:3. After treatments the fruits were placed in hard paper boxes, eight fruits 
per box, then immediately conditioned in cooling conditions of $12 \pm 1.5^{\circ} \mathrm{C}$ e $85-$ $95 \%$ relative humidity $(\mathrm{RH})$, six box per treatments. After 15, 21 e 28 days were transferred to controlled conditions of $25 \pm 2.0{ }^{\circ} \mathrm{C}$ and $85-95 \% \mathrm{RH}$, where it remained for 7,8 and 6 days, respectively. The use of wax and plastic films did not have any influence on the preservation of fruit quality for longer time. The fruits treated with plastics get development fermented flavor. The plastic films PD941 and D-955 retained the development of fruits soluble solids, even though, this had not reflected in longer life of the fruits. The plastic film PP PERF. did not altered the quality of the fruits. The gas composition in the interior of the plastic bag PD-941 was more adequate than the gas composition in the D-955. The fruits with plastic submitted of the plastic film D-955 did not developed skin color normally. The treatment with fruits protected with WAX 1:1 was not effective. The treatment REC. 1:1 was not effective in the maintenance of fruit characteristics. 


\section{INTRODUÇÃO}

A manga pertence ao gênero Mangifera, sendo que, a única espécie conhecida horticulturalmente é a Mangifera indica L.. Originária do sudeste asiático, a cultura da manga disseminou-se para várias regiões do mundo. Mesmo assim, o continente de origem tem se mostrado como o principal produtor da fruta ( São José \& Souza, 1992). É extensivamente cultivada nas regiões tropicais e subtropicais da Ásia, África e Américas. Como frutífera comercial é importante em vários países, notadamente aqueles situados no sudeste da Ásia, tais como, Filipinas, Indonésia e Tailândia. Esta cultura é muito conhecida no Egito, sudeste da África, República Sul Africana, Havaí e ilhas das Índias Ocidentais. Na América Tropical é talvez a fruta mais popular.

Apesar da manga estar presente em 74 países, apenas 68 destes atingem uma produção superior a 1.000 ton/ano. A produção mundial foi de 18,45 milhões de toneladas, em 1994. A Índia destaca-se como maior produtor, sendo responsável por $55 \%$ da produção mundial, seguida pela China, Paquistão, Indonésia, Tailândia, Nigéria e Brasil (FAO, 1995).

O mercado mundial de mangas, em relação à produção mundial, é bastante insignificante. Somente $0,6 \%$ de manga "in natura" é internacionalmente comercializada, porém, isso não significa que a perspectiva de mercado para esta fruta não exista.

Haines (1991), possui uma visão bastante otimista com relação às perspectivas de mercado internacional da manga. Segundo este autor o Brasil tem exportado mangas para o Reino Unido, Estados Unidos da América do 
Norte (EUA), Canadá, entre outros países, apontando ainda, como mercados promissores, o holandês, japonês e a Comunidade Econômica Européia (CEE), totalizando mais de 1,6 milhões de potenciais consumidores. No entanto, este autor ressalta que a conquista destes mercados só se concretizará mediante a adoção de processamentos, manuseio, condições de transportes adequados e de distribuição, com o propósito de se levar a estes lugares produtos com qualidade compatível com as exigências dos mesmos.

Um fator que pode afetar o crescimento da exportação da manga é o alto custo do fruto fresco para os países importadores. Este alto custo está particularmente associado aos preços pagos quando os frutos são exportados por via aérea. Porém, se estes saíssem dos trópicos e alcançassem os mercados das regiões temperadas por via marítima, haveria uma redução significativa dos custos, como mostrou Silva (1994), que para exportar 10 mil toneladas de frutas, por via aérea, nos anos de 1982 a 1990, foi gasto um total de 17,4 bilhões de dólares, ao passo que, por via marítima, o Brasil gastaria apenas 4,0 bilhões de dólares, propondo que o saldo positivo fosse utilizado na melhoria do próprio setor. Contudo, o conhecimento adequado sobre condições de estocagem que permitam recomendações para exportação de frutos por via marítima que garantam a manutenção da qualidade ainda é insuficiente (Medlicott et al., 1990b; Seymour et al., 1990).

Os frutos que se destinam ao mercado externo e que são transportados por via maritima são submetidos à condições de refrigeração, onde a temperatura pode variar de 10 a $13^{\circ} \mathrm{C}$ (Camillo-López et al., 1995; Kalra \& Tandon, 1983; Medlicott \& Jeger, 1987 e Thomas \& Oke, 1983), de acordo com a espécie, grau de maturação do fruto e época de colheita do fruto (Thompson, 1971 e Medlicott \& Jeger, 1987). Para variedades provenientes da Flórida (EUA), Medlicott \& Jeger (1987), recomendam uma temperatura de armazenamento de $12^{\circ} \mathrm{C}$. 
A manga, assim como outros frutos tropicais, é sensivel ao armazenamento refrigerado, o qual pode causar o comprometimento da sua qualidade quando o fruto é exposto a esta condição por períodos prolongados, como no caso do transporte por via marítima. Portanto pesquisas devem ser conduzidas para que se possa determinar tratamentos e técnicas que proporcionem a manutenção da qualidade e a extensão da vida de prateleira do produto.

A combinação de armazenagem frigorífica com atmosfera modificada pela embalagem é uma técnica utilizada para aumentar o tempo de estocagem e a vida de prateleira de produtos frescos altamente perecíveis, como é o caso da manga, para que possam ser transportados por via marítima (McGlasson", citado por Yamashita, 1995).

Outro produto que tem sido usado com tal finalidade é a cera que, quando aplicada à superfície do fruto, forma uma película em volta do mesmo, causando a restrição das trocas gasosas, diminuição da atividade respiratória e, conseqüentemente, prolongamento da vida pós-colheita do fruto.

Embora estudos já tenham sido realizados sobre a conservação da manga, com o objetivo de prolongar o período de armazenamento sob refrigeração em atmosfera modificada para que os frutos atinjam o mercado consumidor apresentando qualidade compatível com as exigências deste mercado, existe a necessidade de se conhecer novas tecnologias e produtos, assim como, o comportamento de novas variedades, quando submetidas a estas condições. Sendo assim, este estudo tem a finalidade de verificar o efeito da aplicação de filmes plásticos e ceras na conservação frigorífica da manga 'Palmer'.

\footnotetext{
${ }^{1}$ MCGLASSON, W. B. Modified atmosphere packaging: matching physical requirements with physiology of produce. Food Australia v. 44, n. 4, p. 168-70, 1992.
} 


\section{REVISÃO BIBLIOGRÁFICA}

\subsection{Ponto de colheita}

A não observação do momento exato em que a manga deve ser colhida, pode causar danos sensiveis à fruta, alterando a sua qualidade, podendo ocorrer até mesmo perdas totais.

A definição de um estádio de maturação do fruto que garanta uma qualidade aceitável pelo consumidor final, implica na necessidade de se desenvolver medidas objetivas para se determinar o ponto ideal de maturação na ocasião da colheita (Reid, 1985).

A manga é uma fruta climatérica e que se caracteriza por uma elevada atividade respiratória e grande capacidade de acúmulo de reservas nutricionais sob a forma de amido. Quando a manga é colhida antes de atingir a fase pré-climatérica, o fluxo de seiva proveniente da planta é interrompido, causando o seu enrugamento devido às perdas por transpiração não serem mais compensadas pela seiva, permanecendo com a polpa esbranquiçada, firme e ácida, mas sem sabor. Neste estádio, a maturação controlada com o uso de etileno ou acetileno não produz efeito. Na fase pré-climatérica, no entanto, a fruta já acumulou todas as suas reservas, e alcançou, portanto, a maturidade fisiológica (Bleinroth, 1989), sendo considerado um bom estádio para o mercado de frutas frescas (Stafford, 1983).

Leley et al. (1943) verificaram que o completo desenvolvimento fisiológico da manga da variedade Alfonso, que é uma das mais cultivadas na Índia, é alcançado só aos 90 dias após a fertilização. Idêntico estudo foi feito com a manga Haden, por Hakness \& Corbin (1950), onde constataram que 
para esta variedade atingir a maturação necessitou de 105 a 115 dias após ser fertilizada.

Vários parâmetros são sugeridos para determinar o estádio de maturação da manga baseando-se no seu aspecto externo e físico, e na composição química na época da colheita (Shewfelt, 1993).

Jauhari \& Tripathi (1972) estudaram a possibilidade de se utilizar a relação peso específico/amido como parâmetro para determinar um "índice de maturação" da manga da variedade Bombay Yellow, assim como teor de amido e a acidez, que foram considerados pelos autores como bons indicadores do ponto de maturação das frutas.

Outros autores, como Bhatnagar \& Subramanyam (1973) e Rao et al. (1972), consideram que além destes índices, para a determinação do ponto de colheita, deve-se fazer a correlação com o teor de sólidos solúveis totais, a relação de açúcares e acidez, assim como a necessidade de se utilizar um índice para detectar a coloração e forma de determinadas variedades de manga.

Outro parâmetro sugerido por Bleinroth (1989), é o fato de no momento do corte do pedúnculo a seiva apresentar-se de cor mais ou menos violeta e consistência muito fluida, indicando que a fruta ainda está imatura. $\grave{A}$ medida que vai atingindo o ponto de colheita a seiva torna-se mais viscosa, esbranquiçada e seca rapidamente, após a colheita do fruto.

Com relação ao aspecto físico da manga, foi analisada a conformação de sua espádua, constatando-se que inicialmente as mangas apresentam as espáduas em linha com o ponto de inserção do pedúnculo e a coloração da casca é verde-oliva. A medida que a espádua vai se elevando, em relação ao ponto de inserção do pedúnculo e a casca iniciar sua mudança de cor verde para ligeiramente amarelada, tem-se o ponto de colheita da manga (Cheema et al., 1950). 
De acordo com Samson (1989) os frutos são geralmente colhidos quando iniciam a mudança de cor ou após o começo do amadurecimento, antes que caiam da planta. Se a sua comercialização for realizada no mercado local, estes podem aguardar na arvore até atingir uma textura mais macia, porém se forem transportados por trem ou navio, para locais mais distantes, podem ser colhidos quando estão ainda verdes e firmes. Este autor recomenda os seguintes parâmetros como os mais precisos para a colheita:

1. Teor de sólidos solúveis totais em torno de $12^{\circ}$ Brix.

2. Gravidade específica de 1,01 a 1,02.

3. Resistência a pressão de 1,75 a $2,0 \mathrm{Kg} / \mathrm{cm}^{2}$.

Entretanto, todos estes índices e parâmetros, variam consideravelmente de uma variedade para outra, não podendo, contudo, generalizá-los a todas as variedades (Krishnamurthy \& Subramanyam, 1973 e Subramanyam et al., 1975).

\subsection{Fisiologia pós-colheita}

As mudanças pós-colheita em manga ocorrem principalmente relacionadas aos eventos associados ao amadurecimento e senescência desde que a manga seja colhida no estado "de vez" (maturidade fisiológica).

Para Subramanyam et al. (1975) os frutos da mangueira não devem ser deixados na planta, pois a maioria deles caem antes de completarem seu amadurecimento. Além disso, os frutos amadurecidos nas árvores têm o sabor e o aroma inferiores àqueles amadurecidos após a colheita, além da manutenção da qualidade ficar reduzida.

A fisiologia do amadurecimento da manga envolve um grande número de atividades metabólicas para resultar em frutos de qualidade aceitável ao consumo (Medlicott et al., 1988). Dessas atividades fisiológicas, as mudanças nos teores de carboidratos e acidez que promovam uma relação 
açúcar/ácido desejável, o desenvolvimento da cor e do sabor característicos das variedades e a maciez da textura, melhorando a qualidade, são de grande importância para o processo de amadurecimento. Todas essas mudanças bioquímicas acontecem num período curto de 10 a 14 dias à temperatura ambiente $\left(30^{\circ} \mathrm{C}, 85 \%\right.$ U.R), dependendo da variedade e estádio de maturação no momento da colheita (Subramanyam et al., 1975).

\subsubsection{Respiração}

Após a colheita do fruto, a respiração torna-se o seu principal processo fisiológico. Durante este processo o fruto passa a utilizar suas próprias reservas para continuar o seu desenvolvimento porém, a energia liberada pela respiração, pode ser utilizada, em alguns casos, para continuar a sintese de pigmentos, enzimas e outros materiais de estrutura molecular elaborada (Chitarra \& Chitarra, 1990).

A manga é um fruto que apresenta uma fisiologia pós-colheita típica dos frutos climatéricos. O estádio de desenvolvimento em que ocorrem o amadurecimento e senescência são marcados por um significativo aumento na taxa de respiração, indicando o princípio do climatério (Bleinroth, 1981).

Em estudos realizados por Leley et al. (1943), com a manga 'Alphonso', foi observado uma ascensão climatérica no início do amadurecimento que, depois de 2 a 5 dias, atingiu o valor máximo, vindo a apresentar diminuição aos 9 dias, quando os frutos já estavam maduros.

Um padrão para a taxa de respiração em diferentes variedades de manga, foi observado por Krishinamurthy \& Subramanyam ${ }^{2}$ e Subramanyam et al. $^{3}$, citados por Krishinamurthy \& Subramanyam, 1973 e Subramanyam et al.,

\footnotetext{
2 KRISHNAMURTHY, S. \& SUBRAMANYAM, H. Respiratory climacteric and chemical changes in the mango fruit (Mangifera indica L.). Journal of the American Society for Horticultural Science, $v$. 95, n. 3, p. 333-7. 1970.

${ }^{3}$ SUBRAMANYAM, H.; MOORTHY, N.V.N.; LAKSHMINARAYANA, S. et al. Studies on harvest, transport and storage of mango. Acta Horticulturae, n. 24, p. 260-4, Mar. 1972.
} 
1975. Este padrão de respiração foi dividido, por estes autores, nas quatro seguintes fases: 1) fase do pré-climatérico, que se estende por 3 dias após a colheita, onde o fruto ainda se encontra verde e firme, e um decréscimo na produção do dióxido de carbono $\left.\left(\mathrm{CO}_{2}\right) ; 2\right)$ elevação climatérica, que se estende por mais 6 dias após a colheita, onde verificou-se um súbito aumento na produção de $\mathrm{CO}_{2}$, mas os frutos ainda permaneciam verdes e firmes; 3) pico climatérico, que ocorreu por volta de 9 dias após a colheita resultando em uma máxima produção de $\mathrm{CO}_{2}$, acompanhada de mudança de cor do fruto, textura mais macia e desenvolvimento do odor característico. 4) senescência, após 10 dias da colheita, com decréscimo na produção de $\mathrm{CO}_{2}$, desenvolvimento de cor atrativa, amolecimento do fruto, odor pronunciado, amadurecimento completo e maior suscetibilidade a infecções provocadas por microrganismos.

Estudos sobre a respiração dos frutos da mangueira estão voltados para a demonstração do processo climatérico em frutos inteiros e em fragmentos. São poucas as informações a respeito da bioquímica dos mitocôndrios e outras frações sub-celulares diretamente envolvidas com o processo respiratório.

Baqui et al. (1974) estudaram a oxidação mitocondrial de vários substratos e também os níveis de enzimas do ciclo de Krebs em mangas que apresentavam três estádios de maturação. As informações indicam que os mitocôndrios em manga estão ativos em todo o estádio do desenvolvimento do fruto, e que durante 0 amadurecimento sua atividade aumenta consideravelmente.

Estudos conduzidos por Lam et al. (1982) mostraram que o aumento da taxa respiratória em mangas da variedade Golek, começa uma semana depois da colheita em frutos imaturos, enquanto que para frutos maduros, o início é três dias após a colheita. As informações indicam que frutos colhidos na fase inicial do processo de maturação tem uma maior vida de 
armazenamento do que os que apresentavam uma fase mais adiantada deste processo.

A respiração climatérica durante 0 amadurecimento do fruto tem grande importância para a vida pós-colheita, pois esse processo demanda grande quantidade de energia. Para 0 armazenamento em baixas temperaturas $\left(5,5\right.$ a $\left.10^{\circ} \mathrm{C}\right)$, a energia demandada durante o amadurecimento pode ser calculada pela taxa de respiração do fruto (Subramanyam et al., 1975). Yamashita (1995), verificou que uma redução na temperatura de armazenamento de $22^{\circ} \mathrm{C}$ para $12^{\circ} \mathrm{C}$, causou uma diminuição na taxa respiratória das mangas embaladas em relação ao controle da ordem de $20 \%$.

A qualidade de mercado do fruto depende da taxa de respiração. Durante a respiração o fruto libera calor e água, ocorrendo ao mesmo tempo a perda de seu peso. Tal processo, juntamente com a transpiração, seria o principal fator destas perdas, de acordo com Krishnamurthy \& Subramanyam (1973). Caso não se controle a velocidade do metabolismo respiratório do fruto, através da redução da temperatura e umidade relativa alta, o mesmo perderá qualidade podendo se tornar imprestável para comercialização (Bleinroth, 1981).

\subsubsection{Etileno}

O etileno é considerado um hormônio de amadurecimento de frutos. Sua evolução acompanha o processo de maturação e envelhecimento, mas em manga, assim como em outros frutos, não se conhece muito bem o mecanismo de ação do etileno. Do mesmo modo, a natureza das reações do etileno na indução do amadurecimento não está claramente compreendida.

Lam et al. (1982) estudaram a produção do etileno em manga da variedade Golek e os resultados mostraram que ocorre um aumento em sua produção após o início do climatério respiratório. O tempo para se atingir o 
pico de produção de etileno aumenta progressivamente de acordo com que se aproxima a maturidade do fruto no momento de colheita. Observou-se que os maiores picos de produção de etileno encontrados foram em frutos imaturos.

O nivel do ácido-1-aminociclopropano carboxílico (ACC) o precursor imediato da biossíntese de etileno, foi estudado por Lizada et al. (1983) em mangas da variedade Carabao. O padrão de produção de ACC nesses frutos diferem daqueles observados durante 0 amadurecimento em outros frutos, como por exemplo o abacate e a banana (Hoffmam \& Yang, 1980). Em manga, o nivel de ACC não exibe um pico, mas uma gradual elevação durante o progresso do amadurecimento. Ocorre redução na síntese de ACC durante o amadurecimento, assim a acumulação líquida de ACC só é evidente quando a enzima sintetizadora de etileno torna-se inativa durante a senescência do tecido.

\subsubsection{Constituição química}

O aumento da taxa respiratória durante o amadurecimento da manga é acompanhado por mudanças químicas que vem sendo estudadas em vários trabalhos. Nesta fruta, como em muitas outras, o sinal mais visível do amadurecimento é a perda da cor verde. De acordo com Medlicott et al. (1986) a perda da coloração verde está associada com a degradação da clorofila e desenvolvimento de pigmentos carotenóides, antocianinas e xantofilas, sendo o $\beta$-caroteno o de maior presença na casca de frutos maduros. Os carotenóides e xantofilas são os pigmentos predominantes dos frutos maduros (Stafford, 1983 e Pantastico et al., 1984, Zagory \& Kader, 1989). Durante o desenvolvimento do fruto, antes de ser alcançado o estado de maturidade fisiológica, são encontrados carotenóides em baixas quantidades (Stafford, 1983). Subramanyam et al. (1975) encontraram um aumento de 20 vezes no total de carotenóides das variedades Alfonso e Pairi, na fase de 
amadurecimento. Os níveis de carotenóides em quatro variedades de manga, no estádio maduro, segundo Vasquez-Salinas \& Lakshiminarayana (1985) foram: $6187(\mu \mathrm{g} / 100 \mathrm{~g})$., para a Haden; 2603 $(\mu \mathrm{g} / 100 \mathrm{~g})$, para a Irwin; $4797(\mu$ $\mathrm{g} / 100 \mathrm{~g})$, para a Kent e $5105(\mu \mathrm{g} / 100 \mathrm{~g})$, para a Keitt.

O açúcar é outro constituinte que aumenta com a maturação da manga. Este causa uma alta proporção de sólidos solúveis, sendo que há maior quantidade de açúcares não-redutores (sacarose). Vasquez-Salinas \& Lakshminarayana (1985) mostram que a glicose se encontra sempre em menor quantidade do que a frutose durante todo o período de amadurecimento, mas esse açúcar não contribui significativamente no incremento do sabor adocicado da manga.

Em contraste com os carotenóides e açúcares, o ácido ascórbico e ácidos totais diminuem nesta fase. Morga et al. (1979) confirmaram o fato de que a maioria dos frutos apresentam redução na vitamina $C$ na pós-colheita. Esses autores encontraram uma redução de aproximadamente $50 \%$ de ácido ascórbico em mangas Carabao, armazenadas por 6 dias à temperatura ambiente $\left(25\right.$ a $\left.30^{\circ} \mathrm{C}\right)$. Já Yamashita (1995), verificou que mangas da variedade 'Keitt' quando foram embaladas em filme plástico e armazenadas a $12^{\circ} \mathrm{C}$, tiveram a menor taxa de degradação da vitamina $\mathrm{C}$, quando comparadas com o controle e outro tipo de embalagem testada. Mangas no pré-climatério (fisiologicamente maduras) contém um nível significativo de ácidos orgânicos, mas em fases mais adiantadas do processo de maturação a maior quantidade desses ácidos se perde. O teor de ácidos em frutos verdes varia entre 4 e 5\% e em frutos maduros de 0,5 a $0,1 \%$ (Subramanyam et al., 1975).

O amadurecimento também provoca importantes mudanças nos componentes da parede celular que conferem mudanças drásticas na textura da manga. Geralmente, ocorre uma redução no tamanho da molécula e esterificação da pectina no decorrer desta fase. A relação entre a distribuição de substâncias pécticas e o amolecimento do tecido em mangas Keitt foram 
estudadas por Roe \& Bruemmer (1981). De acordo com esses autores, a perda de firmeza do fruto está relacionada também com a atividade da celulase e da poligalacturonase, que aumentam marcantemente neste estádio.

De um modo geral, as mudanças nos constituintes químicos que ocorrem durante a vida pós-colheita, que influenciam as qualidades organolépticas dos frutos de manga, são determinadas pela maturidade na colheita, a variedade e o sistema de manuseio pós-colheita (Stafford, 1983).

\subsection{Embalagens utilizadas}

Os frutos, de um modo geral, são produtos que ao serem colhidos, estragam-se com certa facilidade. Esse problema intensifica-se, ainda mais, quando o manuseio é inadequado.

No Brasil, as perdas ocorridas com esses produtos, desde o campo até a comercialização, são consideradas elevadas. Alguns autores chegam a citar percentagens da ordem de 40 a $50 \%$ da quantidade produzida. Algumas razões para este alto índice foram citadas por Ortiz (1980), como: extensas áreas agricultáveis; falta de planejamento de safras; infra-estrutura ineficiente e transporte e manuseio inadequados.

Uma das etapas do beneficiamento dos frutos que, se the fosse dada a merecida importância, causaria considerável redução destas perdas seria a embalagem adequada dos mesmos.

Segundo São José \& Souza (1992), são usadas para frutos comercializados no mercado interno, caixas de madeira tipo $K(495 \times 230 \times$ $335 \mathrm{~mm}$ ) que tem capacidade para 40 a 120 frutos e tipo $M(540 \times 290 \times$ $190 \mathrm{~mm}$ ) com capacidade de, aproximadamente, $27 \mathrm{Kg}$ de frutos dispostos em camadas.

Esses tipos de embalagens apresentam vários inconvenientes $\mathrm{e}$ comprometem a boa qualidade e apresentação do fruto na ocasião da 
comercialização. $O$ modo como são acondicionadas em camadas causa compressão dos frutos das camadas inferiores, amassando-os e ferindo-os durante o manuseio e transporte. A falta de ventilação dentro da caixa, permite a concentração de gás carbônico, ocasionando a fermentação dos frutos, e favorecendo o acúmulo de etileno que acelera a maturação e senescência (São José \& Souza, 1992).

Para a exportação, a embalagem mais utilizada é a caixa de papelão ondulado. Essa caixa possui baixo peso, superfície lisa, capacidade para absorver choques, bom aspecto estético e boa resistência ao empilhamento (Chitarra \& Chitarra, 1990).

A caixa de papelão utilizada para exportação de manga, segundo São José \& Souza (1992), é a do tipo envoltório em peça única, por ser mais econômica do que a do tipo telescópio; mede $390 \times 287 \times 110 \mathrm{~mm}$, apresentando um peso de 5,5 a $6,0 \mathrm{Kg}$. A depender do tamanho dos frutos, cada caixa comporta de 9 a 22 unidades.

As caixas utilizadas na Flórida, Estados Unidos da América do Norte (EUA), são também de papelão ondulado, mas este, na sua confecção, é tratado quimicamente de modo que a absorção da umidade do ar nessas caixas é quase nula (Medina et al., 1981). Segundo os mesmos autores, outros fabricantes produzem caixas parafinadas, que não absorvem a umidade, o que permite o seu armazenamento e maturação em câmara com 90 a $95 \%$ de umidade relativa no ar.

\subsection{Conservação pós-colheita}

\subsubsection{Armazenamento sob refrigeração}

O uso do armazenamento em câmara fria é um dos processos mais conhecidos para se prolongar a vida dos frutos, no entanto, como outras 
frutas tropicais, a manga é suscetível a baixas temperaturas desenvolvendo sintomas de "chilling", friagem, de acordo com Awad (1993). A temperatura em que os sintomas de friagem são verificados variam conforme a variedade, condições horticulturais e estádio de maturação (Lizada at al., 1983).

Segundo Pantastico (1975) vários fatores podem contribuir para o aparecimento de danos causados pelo frio, tais como: variedade, estádio de maturação, tamanho da fruta e tempo de armazenamento. Entretanto, o mesmo autor afirma, com base em trabalhos de vários autores, que a temperatura em que os efeitos dos danos pelo frio começam a aparecer é aproximadamente de $4,4^{\circ} \mathrm{C}$, nos primeiros 3 a 4 dias. Os sintomas destes danos em manga são: amadurecimento impróprio, escurecimento da casca, perda de aroma e sabor, decréscimo no teor de açúcar solúvel, principalmente a sacarose, e acúmulo de minerais na parte lesionada.

Para Thompson (1971) os frutos verdes não devem ser armazenados à temperaturas abaixo de $10^{\circ} \mathrm{C}$, enquanto os totalmente maduros podem ser mantidos a $5^{\circ} \mathrm{C}$, na qual a conservação é possível apenas durante 7 dias.

O'hare \& Prasad (1993) testaram a resposta da variedade Kensigton a baixas temperaturas e recomendam para essa variedade 0 armazenamento a $10^{\circ} \mathrm{C}$ sem que ocorra sintomas de "chilling". Para Akamine (1963), a manga Haden quando madura permite uma boa conservação durante quatro semanas à temperatura de $7,2^{\circ} \mathrm{C}$, mas se for armazenada a $12,8^{\circ} \mathrm{C}$, a sua maturação prossegue. A variedade Alphonso manteve boa qualidade, após ter sido armazenada a $7^{\circ} \mathrm{C}$, durante um período de 2 semanas (Krishnamurthy \& Joshi, 1989). Frutos da variedade Julie armazenados por 26 dias a $7^{\circ} \mathrm{C}$, amadureceram normalmente, após transferência dos mesmos para uma temperatura de $27^{\circ} \mathrm{C}$ (Thompson, 1971).

De acordo com Bleinroth (1973), a temperatura de conservação de mangas em câmaras frigoríficas, variam em torno de 8 a $10^{\circ} \mathrm{C}$ e $90 \%$ de 
umidade relativa, por um período de 3-4 semanas, porém o autor não especifica esta faixa de temperatura em função da variedade.

Em mangas das variedades Malgoa, Malda e Alphonso, Thomas \& Oke (1983) e Kapse et al. (1988), confirmaram que os frutos podem ser armazenados sob baixa temperatura $\left(10 \pm 1^{\circ} \mathrm{C}\right)$, com significativo prolongamento da vida de prateleira.

Para variedades provenientes da Flórida (EUA), Medlicott \& Jeger (1987), recomendam uma temperatura de armazenamento de $12^{\circ} \mathrm{C}$. Armazenamentos a níveis experimentais têm demonstrado que tanto estas, como outras cultivares de mangas, podem ser armazenadas a esta temperatura por um período de 14 a 21 dias (Medlicott et al., 1990b e Miller et al., 1983). Yamashita (1995), estudando varias temperaturas de armazenamento para a variedade Keitt, verificou que a de $12^{\circ} \mathrm{C}$ foi a que mais prolongou a vida de prateleira desta variedade. Já Ramos (1994), trabalhando com as variedades Parvin, Keitt e Tommy Atkins, chegou a resultados semelhantes, porém os frutos foram armazenados a uma temperatura de $14^{\circ} \mathrm{C}$ e submetidos a tratamento hidrotérmico e imersão em cera.

Vários trabalhos realizados com a conservação da manga tem demonstrado que a temperatura está em função da variedade que se pretende armazenar, assim como do estádio de maturação e do tempo que se pretende conservar. 


\subsection{Tratamentos de proteção dos frutos com atmosfera modificada (AM)}

\subsubsection{Uso de filmes plásticos}

A atmosfera modificada, juntamente com o uso da refrigeração, pode atrasar o amadurecimento dos frutos, estendendo, assim, sua vida póscolheita (Coelho, 1994).

Segundo este autor, o processo de respiração do produto armazenado em embalagens de polietileno consome $\mathrm{O}_{2}$ e causa acúmulo de $\mathrm{CO}_{2}$ e água, o que reduz o metabolismo, a síntese e a ação do etileno, e conseqüentemente, evita a perda de água pela transpiração (perda de peso) e o enrugamento.

Muitos trabalhos mostram que 0 uso de embalagens, principalmente sacos de polietileno, reduz acentuadamente as perdas de peso em frutos e hortaliças (Avelar Filho, 1989). Kluge \& Jorge (1992) verificaram que o acondicionamento em sacos de polietileno reduziu bastante as perdas de peso, tanto no armazenamento, quanto na comercialização de ameixas.

Os frutos também podem ser envolvidos individualmente com papel manteiga ou filmes plásticos de polietileno. O uso do papel manteiga apresenta o inconveniente de ser opaco, obrigando o consumidor a removê-lo para avaliação do produto, deixando-o exposto. O filme plástico supera este problema, mas causa outro, ou seja, a poluição ambiental (São José \& Souza, 1992).

Kader et al. (1989), relataram que dentre os filmes plásticos mais usados em embalagens de frutos, destacam-se os poliolefínicos, como o polietileno, polipropileno e polibutileno, assim como os seus copolímeros. Em geral, estes filmes são caracterizados por apresentarem boa barreira ao vapor 
d'água, alta permeabilidade aos gases e favorável resposta à selagem a quente.

A armazenagem da manga Carabao, utilizando-se atmosfera modificada com sacos de polietileno selados, foi suficiente para retardar o amadurecimento por uma semana, durante transporte local (Ben-Yehoshua, 1985), e também para estender a vida de armazenamento da manga Arumanis por mais 3 dias (Yuniarti \& Suhardi, 1992).

Camillo-Lópes et al. (1995) envolveram frutos das mangas "Haden" e "Keitt" em 3 concentrações do filme comestível "Semperfresh", sendo armazenadas à temperatura de $13^{\circ} \mathrm{C}$. Os frutos da variedade Keitt foram tratados com água quente a $46^{\circ} \mathrm{C}$ por 90 minutos antes de serem envolvidos. Foram efetuadas determinações de brix, pH, acidez, firmeza, cor da casca, perda de peso e vitamina $C$. Todas as três concentrações aplicadas para a variedade Haden $(0,8 ; 1,6$ e $2,4 \%)$ afetaram o amadurecimento do fruto. A acidez, firmeza e a cor verde foram acentuadas nos frutos tratados. As concentrações aplicadas para a variedade Keitt $(0,7 ; 1,4$ e 2,1\%) não tiveram efeito na firmeza do fruto, perda de peso e vitamina C. O "Semperfresh" não causou prejuízo ao desenvolvimento dos frutos.

Tentando verificar o efeito do filme plástico como proteção ao desenvolvimento de podridões ocasionadas por fungos, Jagdish-Chandra et al. (1992) observaram que houve redução significativa dessas podridões, em 5 a 8 dias após a inoculação, como resultado da embalagem dos frutos em filme plástico $(0,02 \mathrm{~mm})$.

Yuen et al. (1993) verificaram que empacotando os frutos de manga cultivar Kensington Pride em sacos de polietileno ou sacos encolhíveis, após tratamento com cloreto de cálcio, houve redução significativa de injúrias na casca do fruto.

Hatton \& Reeder (1965), relataram que a manga Keitt apresentou uma boa conservação a uma temperatura de $13^{\circ} \mathrm{C}$ em uma atmosfera contendo 
$5 \%$ de $\mathrm{O}_{2}$ e $5 \%$ de $\mathrm{CO}_{2}$. Nesta atmosfera e sob temperatura de $10^{\circ} \mathrm{C}$, O'hare \& Prasad (1993), constataram que não houve desenvolvimento de sintomas de friagem ("chilling"). Para Kader (1985), a manga apresenta uma conservação regular, quando é submetida a esta mesma atmosfera, sob temperaturas entre $10-15^{\circ} \mathrm{C}$. Sornsrivichai et al. (1989), armazenaram mangas da cultivar Keaw Sawoey, nestas mesmas condições, porém sob baixa pressão, e embaladas em sacos de polipropileno $(0,031 \mathrm{~mm})$, constatando que os frutos não amadureceram e apresentaram fermentação após 1 e 3 semanas durante estocagem a $13^{\circ} \mathrm{C}$.

Os frutos da cultivar Keaw Sawoey embalados em sacos plásticos selados, puderam ser mantidos com uma qualidade aceitável por 6-9 dias e 3036 dias a temperatura ambiente $\left(28\right.$ a $33^{\circ} \mathrm{C}$ com $80 \pm 2 \%$ UR) e a $13^{\circ} \mathrm{C} \mathrm{com}$ $78 \%$ UR, respectivamente (Sornsrivichai et al., 1989). Ramos (1994), conseguiu ampliar o período de conservação de mangas com tratamento térmico em thiabendazole, embaladas em sacos plásticos sob vácuo parcial (TTVA) de 8-13 dias, na testemunha, para 15-18 dias, sob condições ambientais $\left(27,2 \pm 1,44^{\circ} \mathrm{C} ; 71,5 \pm 6,2 \%\right.$ UR) e para $24-27$ dias, quando associado à refrigeração $\left(14,0^{\circ} \mathrm{C} ; 77,0 \%\right.$ UR). Para a cultivar Keitt, Yamashita (1995), conseguiu bons resultados quando utilizou um filme denominado como Copolímero Termoencolhível Cryovac $\AA$ D-955, o qual proporcionou uma conservação do fruto por um período de 33 dias a $12,0^{\circ} \mathrm{C} \pm 1,0^{\circ} \mathrm{C} ; 75-85 \%$ UR e mais 4 dias a $22,0^{\circ} \mathrm{C} \pm 3,0^{\circ} \mathrm{C} ; 65-75 \%$ UR, para amadurecer.

A precisão da concentração dos gases em filmes plásticos, durante armazenamento, é de difícil controle, podendo ser regulada apenas parcialmente (Shewfelt, 1986) através da seleção de filmes com diferentes taxas de permeabilidade gasosa, estádio de amadurecimento do fruto e temperatura de armazenamento (Hatton \& Reeder, 1965 e Miller et al., 1983). 


\subsubsection{Uso de ceras e coberturas de superfície}

A cerosidade natural dos frutos e vegetais restringem as trocas gasosas e a transpiração dos produtos frescos, tendo um efeito similar ao filme plástico (Wang, 1995).

São José \& Souza (1992) observaram que em muitos países a cerosidade do fruto, perdida durante o processo de beneficiamento, lavagem e polimento, tem sido reconstituída pelo uso de cera, aplicada por imersão ou pulverização, que além de reduzir a perda de água, não é tóxica ou poluente e confere aspecto atrativo após a secagem e polimento do fruto.

A cobertura do fruto com ceras reduz a perda de peso, trocas gasosas e retardam o processo de amadurecimento. O prolongamento do período de conservação dos frutos e redução na perda de peso (Chatper et al., 1972 e Sundararaj et al., 1972), diminuição das perdas no transporte marítimo (Sharma \& Kapur, 1967), desenvolvimento do sabor, aroma e cor (Dharkar et al., 1966), tem sido demostrado com relação a utilização de ceras.

Yuniarti \& Suhardi (1992) estudaram diferentes métodos para retardar o amadurecimento de mangas (cv. Arumanis) durante o transporte e minimizar as perdas pós-colheita. Os frutos foram colhidos em um ótimo estádio de maturação e tratados da seguinte maneira: a) solução de cloreto de cálcio $(2,4 ; 6,0$ e $8,0 \%)$; b) emulsão de cera $(4,5,6$ e 7\%); c) envolvidos em sacos de polietileno perfurados, contendo permanganato de potássio $(2,5 ; 5,0$; 7,5 e 10\%), que é um absorvedor de etileno; d) envolvidos em sacos de polietileno e com permanganato de potássio. Os frutos foram colocados em caixas de papelão perfuradas e transportados por 36 horas. Observaram que a emulsão de cera na concentração de 6 a $7 \%$ demonstrou melhor resultado, retardando o amadurecimento por 11 dias, prolongando o estádio de maturação por 9 dias e diminuindo a perda de peso, quando comparado com o controle. Contudo, a emulsão de cera diminuiu a quantidade de sólidos 
solúveis para $14,8 \%$ após o transporte (tratamento de cera a $6 \%$ ) em relação aos $18,8 \%$ do controle.

Frutos de manga Dushehare e Mallika foram tratados com Talprolong (composto de uma mistura de ésteres de sacarose e ácidos graxos), nas concentrações de 1,0 e $1,5 \%$. A concentração de $1 \%$ foi considerada como o melhor tratamento, para um armazenamento de 15 dias a temperatura ambiente, para as duas cultivares, com uma boa manutenção da qualidade dos frutos (Huddar et al., 1988). Resultado semelhante foi encontrado por Krishnamurthy (1988), para a manga Alphonso.

Em trabalho realizado por Castrillo \& Bermudez (1992), frutos da mangueira foram tratados com cera do tipo "Primafresh $\mathrm{C}$ " e "Primafresh 31" a $20 \%$ (concentração original), $10 \%$ e $5 \%$ de sólidos, sendo colocados para amadurecer em ambiente com temperaturas de 25 e $27^{\circ} \mathrm{C}$ e umidade relativa de $80 \%$. A cera, particularmente nas duas maiores concentrações, reduziram a perda de peso durante 0 amadurecimento. A degradação da clorofila no exocarpo e o aumento do $\mathrm{pH}$ no mesocarpo que, normalmente, ocorre na maturação, foram retardadas nas duas maiores concentrações para os dois tipos de cera. Concluíram ainda, que a cera do tipo "Primafresh $\mathrm{C}$ " foi mais efetiva que a "Primafresh 31" nas concentrações similares e não afetou a clorofila do mesocarpo, açúcar e a quantidade de amido.

Shivarana-Reddy \& Thimma Raju (1988) conseguiram reduzir a perda de peso e a deterioração no armazenamento em manga "Alfonso" quando os mesmos foram cobertos com emulsão de cera $(2,4,6$, e $8 \%)$ e tratadas com fungicidas (thiabendazole, benomyl e bavistin a 100, 250 e 500 ppm). Verificaram que o melhor armazenamento foi realizado pelo tratamento dos frutos com thiabendazole (100 ppm) e 6\% de emulsão de cera, o que causou a menor perda de peso, por um período de 20 dias. Nesta mesma concentração, Parmar \& Chundawat (1988), obtiveram um bom resultado no 
retardamento do amadurecimento da manga 'Kesar', porém houve perda na qualidade.

Outros produtos para revestir a manga foram testados por Bose \& Basu (1954), como a parafina, na qual os frutos foram imersos em banhos a 80 ${ }^{\circ} \mathrm{C}$ durante 10 segundos e o tratamento com solução de $50 \%$ de parafina e éter de petróleo, também durante 10 segundos. Com esses tratamentos observouse que a intensidade respiratória das mangas foi de 2,2 e $8,04 \mathrm{mg}$ de $\mathrm{CO}_{2} / \mathrm{Kg} / \mathrm{h}$, respectivamente, em comparação com os frutos não tratados que foi de $9,70 \mathrm{mg}$ de $\mathrm{CO}_{2} / \mathrm{Kg} / \mathrm{h}$. A perda de peso dos frutos revestidos com parafina foi de $2,34 \%$ e os não tratados $11 \%$ após 192 horas de armazenamento à temperatura de $25^{\circ} \mathrm{C}$ e $90 \%$ de umidade relativa. Os frutos com parafina puderam ser armazenados durante 42 dias à temperatura de $12,8^{\circ} \mathrm{C}$ e $90 \%$ de umidade relativa, enquanto os sem revestimento conservaram-se apenas por 14 dias.

Ramos (1994), constatou que a aplicação de cera ("Sta. Fresh"/3:7) e a proteção do fruto com saco plástico sob vácuo parcial, foram os tratamentos mais eficazes na prevenção da perda de peso dos frutos, quando mantidos sob refrigeração.

Cuidados devem ser tomados com relação à espessura da camada de cera a ser aplicada. Quando muito fina, não apresenta efeito quanto a perda de umidade (Chitarra \& Chitarra, 1990). Sob condições ambientais, uma quantidade excessiva de cera provoca o desenvolvimento de sabores estranhos, sendo este efeito retardado sob condições de refrigeração (Coelho, 1994). 


\section{MATERIAL E MÉTODOS}

\subsection{Origem, colheita e preparo dos frutos}

Os frutos foram obtidos em um pomar comercial em franca produção, localizado no município de Estivas Gerbi-SP, de propriedade do Sr. Mumeo Takarashi.

A colheita foi realizada em $24 / 01 / 96$, pela manhã. Os frutos foram colhidos com completo desenvolvimento fisiológico (maturidade fisiológica), apresentando a coloração da casca ainda verde e consistência da polpa dura. As mangas foram colhidas manualmente, com auxilio de tesouras para cortar o pedúnculo com aproximadamente $4 \mathrm{~cm}$ de comprimento, o que evita 0 derramamento do látex no fruto. Após a retirada da planta, os frutos foram colocados em caixas plásticas, forradas com jornal; cada caixa recebia 40 frutos, aproximadamente. Depois de acondicionados foram colocados em uma caminhonete e transportados para a plataforma de recepção do Centro de Tecnologia de Hortifruticolas (FRUTOTEC), do Instituto de Tecnologia de Alimentos - ITAL, localizado no município de Campinas-SP. Os frutos foram então espalhados no chão (o qual no dia anterior foi lavado e desinfetado), forrado com jornal, onde passaram à noite, para serem manuseados pela manhã.

No dia seguinte, as mangas passaram por uma seleção quanto ao tamanho, injúrias e estádio de maturação, visando a uniformização do lote, e posteriormente, tiveram o seu pedúnculo cortado com cerca de $2 \mathrm{~cm}$. 


\subsection{Descrição da cultivar}

Campbell (1993), ao descrever as caracteristicas de algumas cultivares de manga da Flórida (EUA), quanto a importância comercial e potencial para exportação, colocou a cultivar Palmer no grupo 2, de um total de 6 grupos, de acordo com o volume de produção das cultivares mais comuns daquela região. Para esta cultivar a descrição do fruto foi a seguinte:

- Frutos oblongos com a base e ápice arredondados;

- Peso médio entre 510 a $850 \mathrm{~g}$;

- Gradiente de cor de amarelo-alaranjado a vermelho escuro e vermelho carmesim;

- Casca grossa, consistente e aderente;

- A polpa é laranja-amarelada, firme que se funde em aroma e moderado sabor e aroma;

- Possui boa qualidade comestível, com pouca fibra na polpa;

Na Flórida (EUA), este mesmo autor comenta que a colheita se dá de julho a final de setembro. Para as condições onde os frutos utilizados neste estudo foram colhidos, o produtor informou que o período de colheita se dá de janeiro a março, a depender das condições climáticas.

\subsection{Tratamento fungicida dos frutos}

Todo o lote foi tratado com uma solução fungicida, contendo 1000 ppm de Sportak $450 \mathrm{CE}$ ( $450 \mathrm{~g} / \mathrm{l}$ de prochloraz), à temperatura de $22 \pm 3^{\circ} \mathrm{C}$. Os frutos ficaram submersos, nesta solução, durante um período de 2 minutos. Após o tratamento os frutos foram expostos ao ambiente $\left(25-30^{\circ} \mathrm{C}\right)$ para secagem da solução aplicada. 


\subsection{Filmes plásticos e ceras utilizadas}

\subsubsection{Filmes plásticos}

- Poliolefínico (D-955), com espessura da parede simples de $21 \pm$ 1,68 $\mu \mathrm{m}$; taxa de permeabilidade aos gases $\left(\mathrm{TPO}_{2}\right.$ e $\left.\mathrm{TPCO}_{2}\right)$ e ao vapor de água (TPVA), de $7 \mathrm{~cm}^{3} \cdot \mathrm{m}^{-2} \cdot d i a^{-1}, 34 \mathrm{~cm}^{3} \cdot \mathrm{m}^{-2} \cdot \mathrm{dia}^{-1}, 17,8 \mathrm{~g}$ água. $\mathrm{m}^{-2} \cdot \mathrm{dia}^{-1}$, respectivamente; e, em forma de bolsa com dimensões de $69,0 \times 35,0 \mathrm{~cm}$.

- Poliolefínico (PD-941), com espessura da parede simples de 20 $\pm 0,99 \mu \mathrm{m}$; taxa de permeabilidade aos gases $\left(\mathrm{TPO}_{2}\right.$ e $\left.\mathrm{TPCO}_{2}\right)$ e ao vapor de água (TPVA), de $9 \mathrm{~cm}^{3} \cdot \mathrm{m}^{-2} \cdot d i a^{-1}, 59 \mathrm{~cm}^{3} \cdot \mathrm{m}^{-2} \cdot d i a^{-1}, 50,2 \mathrm{~g}$ água. $\mathrm{m}^{-2} \cdot d i a^{-1}$, respectivamente; e, em forma de bolsa com dimensões de $66,0 \times 37,0 \mathrm{~cm}$.

- Polipropileno Perfurado (PP PERF), com espessura da parede simples de $44 \pm 4,62 \mu \mathrm{m}$; taxa de permeabilidade aos gases $\left(\mathrm{TPO}_{2}\right.$ e $\left.\mathrm{TPCO}_{2}\right)$, neste caso foi igual à do ambiente; (TPVA) $>170 \mathrm{~g}$ água. $\mathrm{m}^{-2} \cdot$ dia $^{-1}$; diâmetro dos furos de 0,8 a $1,2 \mathrm{~mm} ; 22$ furos. pol $^{-2}$; e, em forma de bolsa com dimensões de $60,0 \times 35,5 \mathrm{~cm}$.

As embalagens plásticas foram analisadas e caracterizadas no Centro de Tecnologia de Embalagens de Alimentos - CETEA, do ITAL, segundo metodologias descritas por Padula et al. (1989).

\subsubsection{Ceras e recobrimento}

- Cera A: cera de base aquosa, livre de solvente. Sua formulação está baseada em emulsão de carnaúba aditivada com impermeabilizantes de grau alimentício.

- Cera B: cera de base aquosa, composta basicamente de resinas fumáricas extraídas de pinus, polímeros e etilenoglicóis. 
- Recobrimento (REC.): composta de resina natural, tensoativo aniônico, solventes glicólicos, neutralizante e preservante.

A composição das ceras e da película sintética foram cedidas pelos fabricantes das mesmas.

A aplicação destes produtos nos frutos foi realizada com pulverizador marca SCHULZ - MS-V 15/200 (Pressão Máxima: 120 lb., Vazão: 426 I./min. e Rotação: 580 RPM), diluídos da seguinte maneira: uma parte do produto para uma parte de água (1:1), e uma parte do produto para três partes de água (1:3). Após a aplicação dos produtos, os frutos foram expostos ao ambiente $\left(25-30^{\circ} \mathrm{C}\right)$ para secagem destes produtos.

\subsection{Embalagem}

Foi utilizada uma embalagem de papelão tipo envoltório em peça única, com dimensões de $342 \times 255 \times 104 \mathrm{~mm}$, onde foram colocados 8 frutos/caixa, com peso líquido médio de $4,124 \mathrm{Kg}$, um pouco menos do que o descrito por São José \& Souza (1992). Esta embalagem foi utilizada em todos os tratamentos do experimento.

\subsection{Tratamentos}

Os tratamentos foram compostos da seguinte maneira:

- Controle: as mangas sofreram apenas tratamento fungicida e foram colocadas na embalagem de papelão.

- D-955: as mangas foram embaladas em saco plástico denominado Poliolefínico D-955.

- PD-941: as mangas foram embaladas em saco plástico denominado Poliolefínico PD-941. 
- PP PERF.: as mangas foram embaladas no saco plástico denominado Polipropileno Perfurado.

- CERA A 1:1: as mangas foram pulverizadas com a 'CERA A' na diluição de 1:1.

- CERA A 1:3: as mangas foram pulverizadas com a 'CERA A' na diluição de 1:3.

- CERA B 1:1: as mangas foram pulverizadas com a 'CERA B' na diluição de 1:1.

- CERA B 1:3: as mangas foram pulverizadas com a 'CERA B' na diluição de 1:3.

- REC. 1:1: as mangas foram pulverizadas com 0 'RECOBRIMENTO' na diluição de 1:1.

- REC. 1:3: as mangas foram pulverizadas com $\circ$ 'RECOBRIMENTO' na diluição de 1:3.

Uma vez embaladas, as mangas foram colocadas em câmara frigorifica previamente regulada a uma temperatura de $12 \pm 1,5^{\circ} \mathrm{C}$ e $85-95 \%$ UR (câmara de refrigeração). Após períodos estabelecidos, as mangas eram transferidas para outra câmara com temperatura de $25 \pm 2{ }^{\circ} \mathrm{C}$ e $85-95 \%$ UR (condições de ambiente), sendo monitoradas por um termohigrográfo - TH 508 , com escala de temperatura de +50 a $-30{ }^{\circ} \mathrm{C}$ e umidade de 0 a $100 \%$; regulado por saturação de umidade $(100 \%)$ e a temperatura por um termômetro de referência, de marca INCOTERM, com escala de -30 a $+50^{\circ} \mathrm{C}$, e divisões de $0,1^{\circ} \mathrm{C}$.

Desta forma, seis caixas por tratamento foram colocadas na câmara de refrigeração, sendo cada uma transferida para as condiçōes de ambiente aos 15, 21 e 28 dias, onde permaneceram por mais 7, 8 e 6 dias, completando um período total de armazenamento de 22, 29 e 34 dias, respectivamente, conforme demostrado na Tabela 1 . As embalagens foram retiradas durante o processo de transferência dos frutos. 
Tabela 1. Descrição dos tratamentos utilizados no experimento e os tempos de permanência na câmara frigorífica, condições controladas e o tempo total, desde a instalação até a avaliação final dos resultados.

\begin{tabular}{|c|c|c|c|}
\hline Tratamentos & $\begin{array}{c}\text { Tempo na câmara } \\
\text { frigorífica (dias) }\end{array}$ & $\begin{array}{c}\text { Tempo em condições } \\
\text { controladas (dias) }\end{array}$ & $\begin{array}{c}\text { Tempo total } \\
\text { (dias) }\end{array}$ \\
\hline & 15 & 7 & 22 \\
\hline \multirow[t]{2}{*}{ Controle } & 21 & 8 & 29 \\
\hline & 28 & 6 & 34 \\
\hline & 15 & 7 & 22 \\
\hline \multirow[t]{3}{*}{ D-955 } & 21 & 8 & 29 \\
\hline & 28 & 6 & 34 \\
\hline & 15 & 7 & 22 \\
\hline \multirow{3}{*}{ PD-941 } & 21 & 8 & 29 \\
\hline & 28 & 6 & 34 \\
\hline & 15 & 7 & 22 \\
\hline \multirow[t]{3}{*}{ PP PERF. } & 21 & 8 & 29 \\
\hline & 28 & 6 & 34 \\
\hline & 15 & 7 & 22 \\
\hline \multirow{2}{*}{ CERA A 1:1 } & 21 & 8 & 29 \\
\hline & 28 & 6 & 34 \\
\hline & 15 & 7 & 22 \\
\hline \multirow{2}{*}{ CERA A $1: 3$} & 21 & 8 & 29 \\
\hline & 28 & 6 & 34 \\
\hline \multirow{3}{*}{ CERA B $1: 1$} & 15 & 7 & 22 \\
\hline & 21 & 8 & 29 \\
\hline & 28 & 6 & 34 \\
\hline \multirow{3}{*}{ CERA B $1: 3$} & 15 & 7 & 22 \\
\hline & 21 & 8 & 29 \\
\hline & 28 & 6 & 34 \\
\hline \multirow{3}{*}{ REC. $1: 1$} & 15 & 7 & 22 \\
\hline & 21 & 8 & 29 \\
\hline & 28 & 6 & 34 \\
\hline \multirow{3}{*}{ REC. $1: 3$} & 15 & 7 & 22 \\
\hline & 21 & 8 & 29 \\
\hline & 28 & 6 & 34 \\
\hline
\end{tabular}




\subsection{Parâmetros analisados}

As análises foram iniciadas em 25 de janeiro de 1996, antes do inicio do armazenamento frigorífico (tempo 0), através da média de 10 frutos escolhidos ao acaso, os quais serviram como padrão de todo lote. As outras análises seguiram o cronograma citado anteriormente, cujo os dados foram obtidos de 7 frutos.

Cor da Casca - A coloração da casca foi determinada através de escala de notas, variando de 1 a 5 (Foto 1 ), onde: $1=$ Fruto verde com laivos arroxeados; 2= Fruto verde com leve pigmentação amarela; 3=Fruto com $1 / 3$ a $1 / 2$ da superfície amarelada, com traços avermelhados e numerosas lenticelas, bem visíveis; $4=$ Fruto com cerca de $2 / 3$ da superfície amarelada, com traços avermelhados e numerosas lenticelas amarelas; $5=$ Fruto de cor laranjaamarelada com laivos vermelhos-brilhantes na superfície (adaptado de Donadio et al., 1982).

Cor da Polpa - foi determinada utilizando-se a escala de notas, variando de 1 a 5 (Foto 2), onde: 1= Branco; 2= Branco-amarelado; 3= Amarelo; 4= Amarelo-laranja; 5= Laranja, de acordo com Medlicott et al. (1990a).

Textura - foi determinada pelo uso de um penetrômetro manual, modelo BISHOP, com escala de 0,5-13 kg e ponteira de $8 \mathrm{~mm}$, procedendo-se uma leitura em lados opostos da seção equatorial dos frutos, após a remoção de uma porção da casca (Medlicott, 1985). O valor obtido para se determinar a textura foi definido pelo máximo de força requerida para que uma parte da 


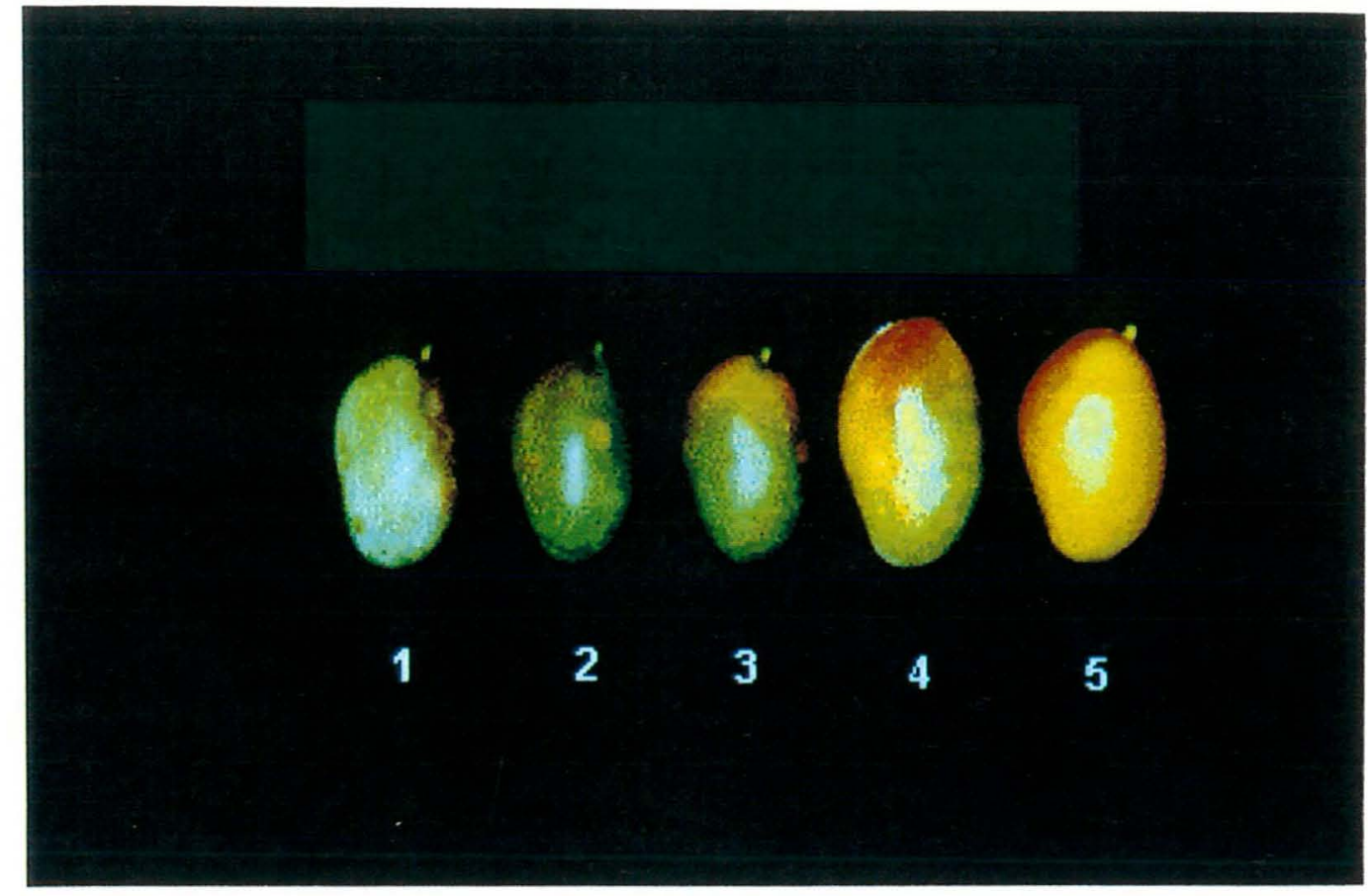

Foto 1. Escala de cor da casca para a manga 'Palmer'.

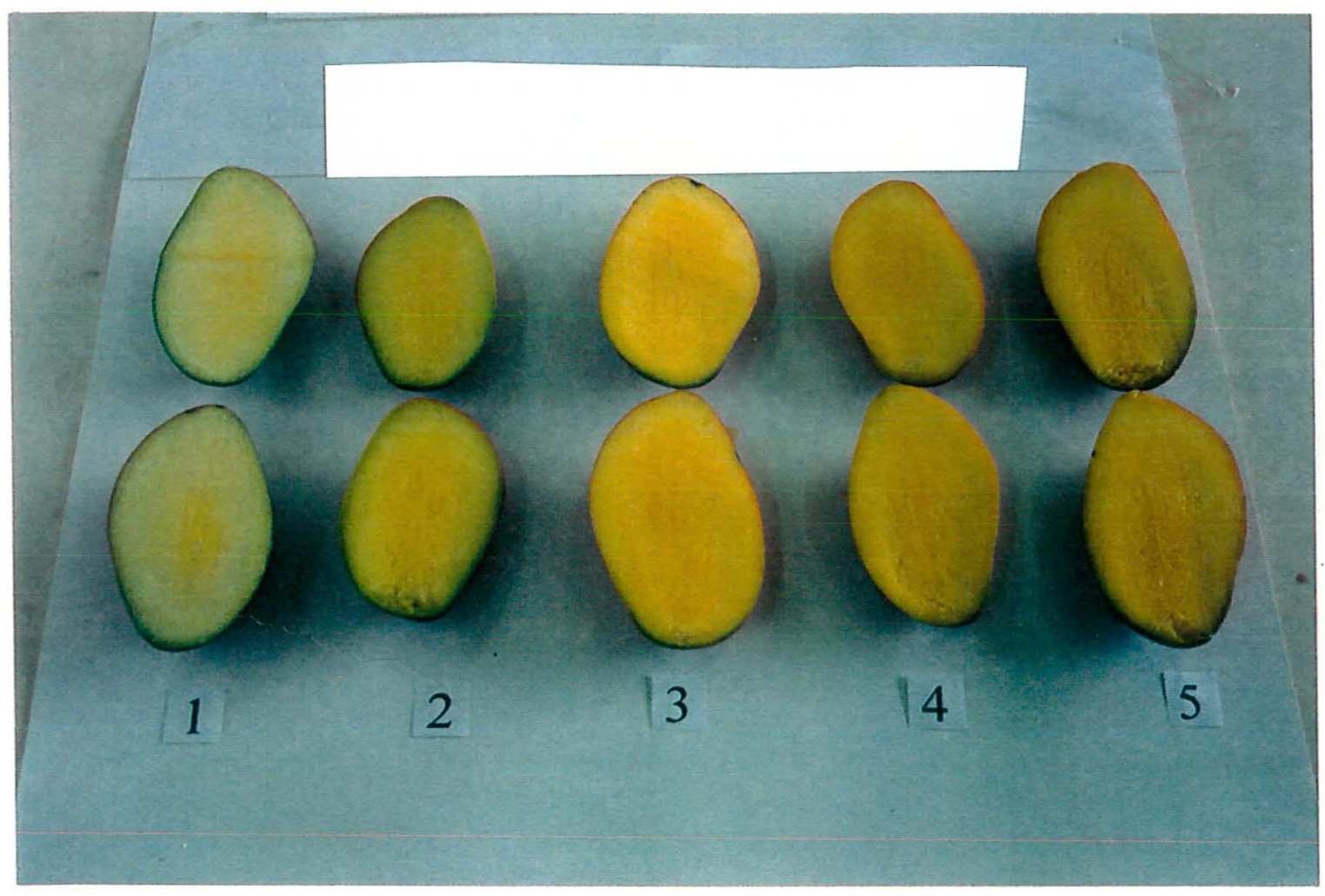

Foto 2. Escala de cor da polpa para a manga 'Palmer'. 
ponteira penetrasse na polpa do fruto (Blanpied et al. ${ }^{4}$, citado por Medlicott, 1985).

Sólidos Solúveis - foi realizada através da leitura refratométrica direta, em graus Brix, a $20^{\circ} \mathrm{C}$, com refratômetro tipo Abbe com escala de graus Brix e divisões de, no mínimo 0,2 (Pearson, 1973 e Harman \& Watkins, 1981), marca TAIGO - N1.

Foram retidas duas amostra de cada fruto, à medida que os frutos iam sendo abertos em duas bandas, coletava-se suco suficiente, de cada lado, para se realizar a leitura, no aparelho.

Acidez Total - o conteúdo de acidez titulável, expresso em gramas de ácido cítrico por 100 gramas de polpa, foi determinado, em três amostras, através da titulação de 10 gramas de polpa homogeneizada e diluída para $90 \mathrm{ml}$ de água destilada, com solução padronizada de hidróxido de sódio a $0,1 \mathrm{~N}$, tendo como indicador o ponto de viragem da fenolftaleína que se dá quando o potenciômetro atinge $\circ \mathrm{pH} 8,1$ (Association of Official Analytical Chemists, 1980). Os aparelhos utilizados nesta determinação foram: pHmetro digital - METTLER 320, com calibração em dois pontos $(4,0$ e 7,0$)$, e duas casas decimais; balança METTLER - P1200N - carga máxima de $1200 \mathrm{~g} \mathrm{e}$ divisão de $10 \mathrm{mg}$; centrifuga WALITA - HL 3236 e bureta de $25 \mathrm{ml}$ com divisões de $0,1 \mathrm{ml}$.

$\mathrm{pH}$ - A leitura de $\mathrm{pH}$ foi realizada com o mesmo material utilizado para a determinação da acidez titulável, onde, antes da adição do hidróxido de sódio a $0,1 \mathrm{~N}$, fazia-se a leitura no mesmo pHmetro, com a solução em constante homogeneização (Pregnolatto \& Pregnolatto, 1985).

${ }^{4}$ BLANPIED, G.D.; BRAMLAGE, W.J.; DEWEY, D.H. et al. A standardized method for collecting apple pressure data. New York's Food and Life Sciences Bulletin, v. 74, p. $2-8,1978$. 
Composição gasosa do espaço-livre - Aos 4, 7, 11, 14, 18, 21 e 28 dias de estocagem a $12{ }^{\circ} \mathrm{C} / 85-90 \%$ UR, as amostras dos filmes plásticos foram avaliadas quanto a composição gasosa do espaço-livre.

A determinação da composição gasosa em termos de oxigênio, nitrogênio e gás carbônico se resumiu na coleta de alíquotas de $300 \mu \mathrm{l}$ de gás do espaço-livre, através de um septo, com seringa hermética e posterior quantificação em cromatógrafo a gás CG - Instrumentos Científicos, série 2527, operando com colunas Peneira Molecular $5 \mathrm{~A}\left(\mathrm{O}_{2}\right.$ e $\left.\mathrm{N}_{2}\right)$ e Porapak Q $\left(\mathrm{CO}_{2}\right)$ e detetor de condutividade térmica. Os resultados de cromatografia foram analisados por um integrador processador CG 100, com base em curvas padrões feitas com gases de calibração e os resultados foram expressos em termos de porcentagem em volume de gás.

A determinação da concentração de etileno no espaço-livre se resumiu na coleta de alíquotas do espaço-livre, através de um septo, com seringa hermética e posterior quantificação em cromatógrafo CG - Instrumentos Científicos, série 37370, operando com coluna Porapak Q e detetor de ionização de chama. Os resultados de cromatografia foram analisados por um integrador CG 200. A quantificação do etileno foi feita por padronização externa, utilizando como padrão $1 \mathrm{ppm}$ de etileno em nitrogênio (p/p). Cada embalagem foi analisada em duplicata e os resultados foram expressos em termos de $\mu \mathrm{g}$ de etileno por litro de espaço-livre da embalagem (Padula et al., 1989).

Análise sensorial (Sabor/Odor) - Aos 8 e 6 dias de transferência para as condições controladas, após 21 e 28 dias passados na câmara de refrigeração, respectivamente, as mangas foram avaliadas quanto ao odor $e$ quanto ao sabor. Utilizou-se a escala de categoria estruturada de nove pontos, apresentada na ficha de avaliação sensorial da manga (ver apêndice). As 
avaliações das alterações sensoriais foram realizadas por uma equipe de dez provadores. Este parâmetro foi avaliado apenas nos tratamentos com filme plástico, ou seja, PD-941, PP PERF. e D-955, além do controle.

\subsection{Análise estatística}

O experimento foi analisado estatisticamente através do teste $F$ para verificar a significância estatística entre os tratamentos. As medias foram comparadas entre si através do teste de Tukey, utilizando-se o procedimento GLM do programa SAS (SAS INSTITUTE INC., 1985). 


\section{RESULTADOS E DISCUSSÃO}

\subsection{Análise dos parâmetros físicos e químicos das mangas submetidas aos diferentes tratamentos e armazenadas a $12^{\circ} \mathrm{C}$ durante 15,21 e 28 dias, sendo em seguida transferidas para $25^{\circ} \mathrm{C}$ por 7,8 e 6 dias, respectivamente.}

Nesta fase os frutos submetidos aos diferentes tratamentos, depois de serem armazenados por 15 dias na câmara frigorífica, foram transferidos para as condições controladas, onde permaneceram por mais 7 dias (22 dias) para se avaliar a evolução do amadurecimento. Este mesmo procedimento foi adotado aos 21 e 28 dias de armazenamento a $12^{\circ} \mathrm{C}$, onde os frutos passaram mais 8 ( 29 dias) e mais 6 (34 dias) em condições controladas, respectivamente.

Durante estes períodos foram realizadas as análises químicas e físicas dos frutos, de acordo com as metodologias descritas no capítulo 3, cujos resultados, após serem analisados estatisticamente, estão descritos e discutidos no decorrer deste capítulo.

\section{a) $\mathrm{pH}$}

Durante o armazenamento frigorífico $\mathrm{O} \mathrm{pH}$ dos frutos variou de 3,50 no tratamento PP PERF. a 3,93 no tratamento PD-941 (Figura 1 (A) e Tabela 2), portanto uma faixa de $\mathrm{pH}$ muito estreita, onde pode-se dizer que os frutos apresentaram um comportamento semelhante nos diversos tratamentos a 

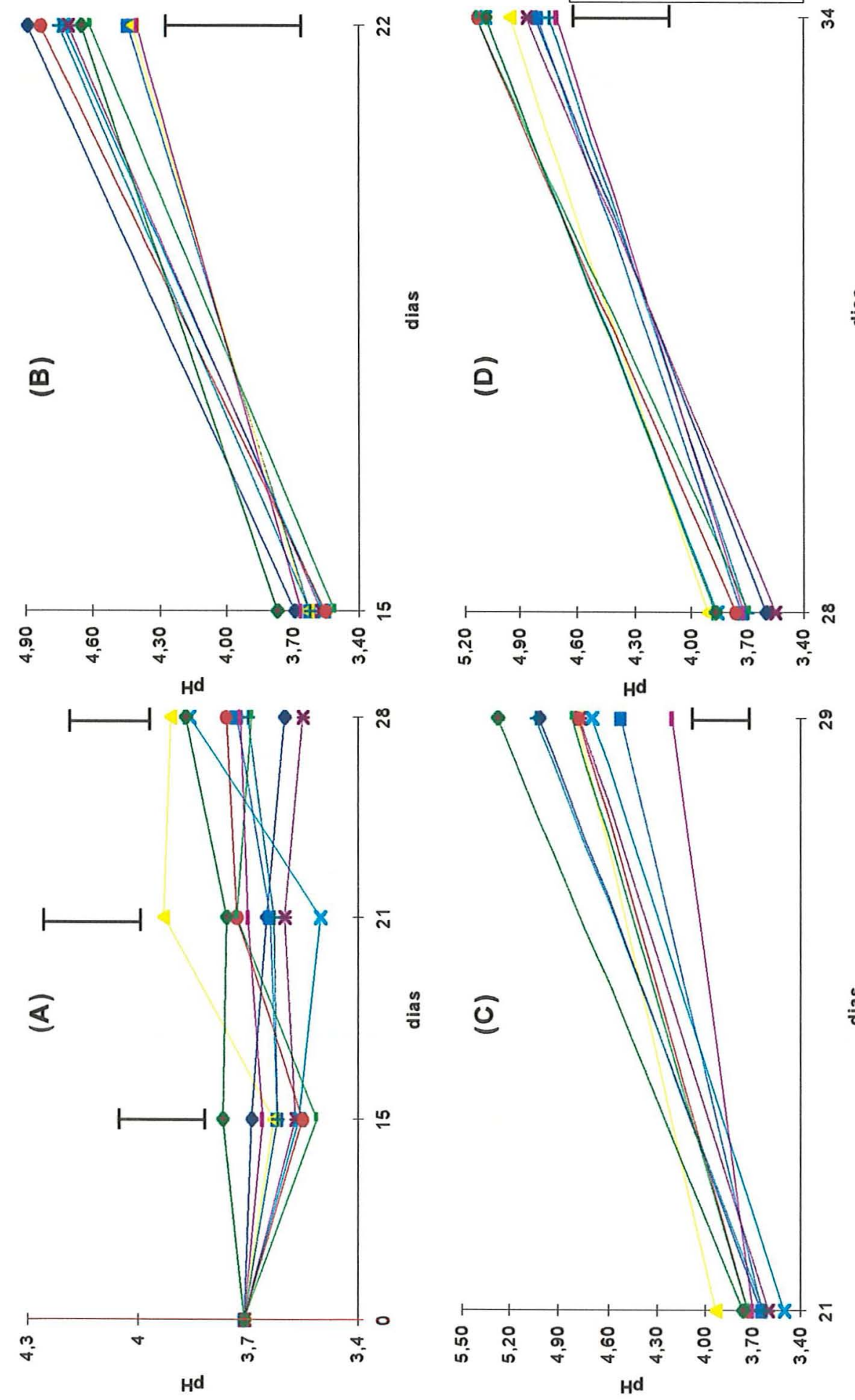

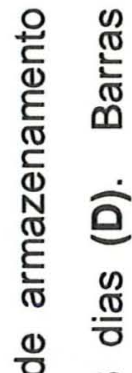

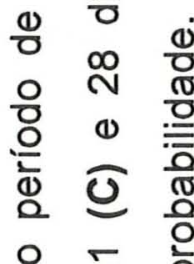

음

ㄷ 흠

壳

ஸे

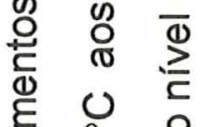

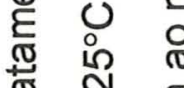

(⿻)

ฆ ญ

닌 ․ㅡㄴ 으

此

施㐫

ก ฐ

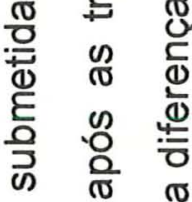

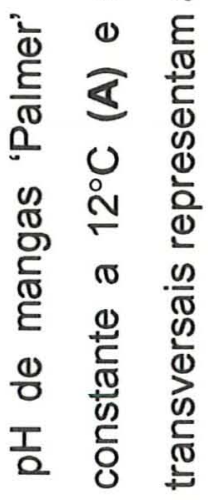

음

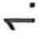

흔 


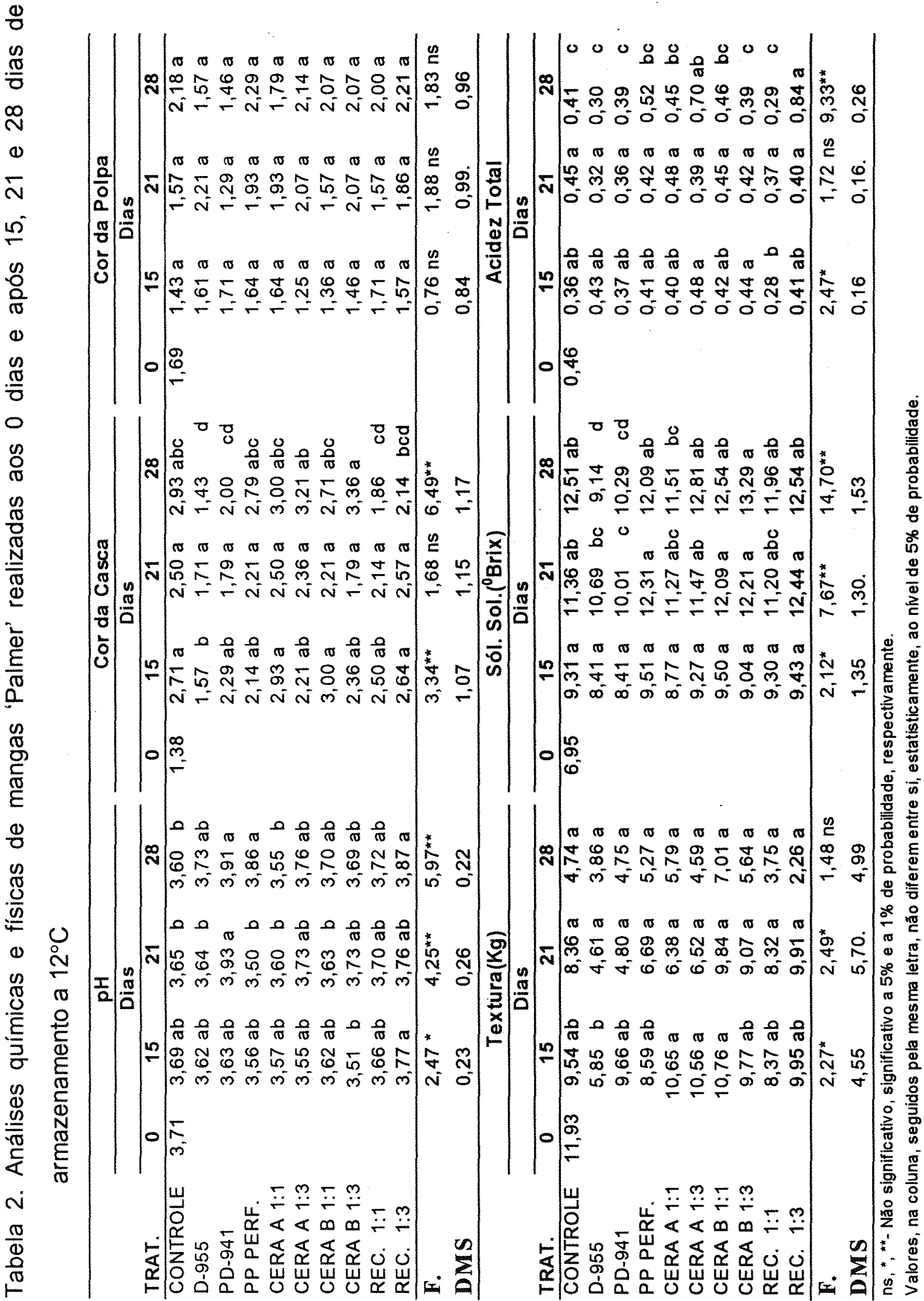


que foram submetidos, embora alguns deles tenham mostrado oscilações, que podem ser atribuídas com maior probabilidade a uma desuniformidade no estádio de maturação dos frutos, os quais apresentaram esta característica para a maioria dos parâmetros analisados neste trabalho. Pouca variação do $\mathrm{pH}$ foi encontrada em estudos realizados por Seymour et al. (1990) e Medlicott (1985), em mangas 'Amelie' e 'Kent' e 'Tommy Atkins', respectivamente, durante armazenamento a $12^{\circ} \mathrm{C}$.

A Figura 1 (B) e Tabela 3 , mostram o desenvolvimento do $\mathrm{pH}$, dos tratamentos que permaneceram 15 dias na câmara frigorífica e depois foram transferidos para as condições controladas por 7 dias. Percebe-se que o $\mathrm{pH}$ dos frutos evoluiu atingindo valores comparáveis aos observados por Morga et al. (1979) em mangas 'Carabao', armazenadas por 7 dias a temperatura de 28 a $32^{\circ} \mathrm{C}$ e $64-67 \%$ UR e por Castrillo \& Bermudez (1992) em mangas 'Bocado', armazenadas por 12 dias a temperatura de $25 \pm 2^{\circ} \mathrm{C}$ e $80 \%$ UR, no entanto os tratamentos se comportaram de maneira semelhante ao controle e nenhuma diferença estatística foi constatada. $A$ elevação no pH tem sido associada, por Medlicott \& Jeger (1987), com a utilização de ácidos orgânicos em excesso, armazenados nos vacúolos como substratos respiratórios.

O comportamento das mangas transferidas aos 21 e aos 28 dias, podem ser visualizados nas Figuras 1. (C) e (D) e Tabelas 4 e 5 , respectivamente, onde constata-se a mesma tendência de evolução do $\mathrm{pH}$, observada para os tratamentos da Figura 1 (B), entretanto nota-se que os tratamentos D-955 e REC. 1:1, transferidos aos 21 dias (Figura 1 (C)), tiveram um efeito negativo com relação a evolução deste parâmetro, os quais apresentaram diferença estatística quando comparados com o controle. 
Tabela 3. Análises químicas e físicas de mangas 'Palmer' realizadas aos 15 dias de armazenamento a $12^{\circ} \mathrm{C}$ e após 7 dias (22 dias) da transferência para $25^{\circ} \mathrm{C}$.

\begin{tabular}{|c|c|c|c|c|c|c|}
\hline \multirow[b]{3}{*}{ TRAT. } & \multicolumn{2}{|c|}{$\mathrm{pH}$} & \multicolumn{2}{|c|}{ Cor da Casca } & \multicolumn{2}{|c|}{ Cor da Polpa } \\
\hline & \multicolumn{2}{|c|}{ Dias } & \multicolumn{2}{|c|}{ Dias } & \multicolumn{2}{|c|}{ Dias } \\
\hline & 15 & 22 & 15 & 22 & 15 & 22 \\
\hline CONTROLE & $3,69 \mathrm{ab}$ & $4,89 a$ & $2,71 \mathrm{a}$ & $3,64 \mathrm{a}$ & $1,43 \mathrm{a}$ & $3,57 \mathrm{a}$ \\
\hline D-955 & $3,62 \mathrm{ab}$ & $4,44 \mathrm{a}$ & $1,57 \mathrm{~b}$ & $3,50 a$ & $1,61 \mathrm{a}$ & $3,07 \mathrm{ab}$ \\
\hline PD-941 & $3,63 a b$ & $4,42 a$ & $2,29 a b$ & $3,29 a$ & $1,71 \mathrm{a}$ & $3,21 \mathrm{ab}$ \\
\hline PP PERF. & $3,56 a b$ & $4,73 a$ & $2,14 a b$ & 3,79 a & $1,64 a$ & $3,39 a b$ \\
\hline CERA A $1: 1$ & $3,57 \mathrm{ab}$ & $4,71 \mathrm{a}$ & $2,93 a$ & $3,50 \mathrm{a}$ & $1,64 a$ & $3,21 \mathrm{ab}$ \\
\hline CERA A $1: 3$ & $3,55 a b$ & $4,83 a$ & $2,21 a b$ & $3,71 \mathrm{a}$ & $1,25 \mathrm{a}$ & 3,64 a \\
\hline CERA B $1: 1$ & $3,62 a b$ & $4,75 a$ & $3,00 a$ & 3,36 a & $1,36 a$ & $3,36 a b$ \\
\hline CERA B 1:3 & $3,51 \quad b$ & $4,61 \mathrm{a}$ & $2,36 a b$ & $3,43 a$ & $1,46 a$ & $3,71 a$ \\
\hline REC. $1: 1$ & $3,66 a b$ & $4,40 a$ & $2,50 a b$ & $2,86 a$ & $1,71 a$ & $2,64 \quad b$ \\
\hline REC. $1: 3$ & $3,77 \mathrm{a}$ & $4,65 \mathrm{a}$ & $2,64 \mathrm{a}$ & $2,86 a$ & $1,57 \mathbf{a}$ & $3,36 \mathrm{ab}$ \\
\hline F. & $2,47^{*}$ & $1,72 \mathrm{~ns}$ & $3,34^{* *}$ & $1,85 \mathrm{~ns}$ & $0,76 \mathrm{~ns}$ & $2,57^{*}$ \\
\hline \multirow[t]{3}{*}{ DMS } & 0,23 & 0,61 . & 1,07 & 1,10 & 0,84 & 0,90 \\
\hline & \multicolumn{2}{|c|}{ Textura $(\mathrm{Kg})$} & \multicolumn{2}{|c|}{ Sól. Sol. $\left({ }^{0} \mathrm{Brix}\right)$} & \multicolumn{2}{|c|}{ Acidez Total } \\
\hline & \multicolumn{2}{|c|}{ Dias } & \multicolumn{2}{|c|}{ Dias } & \multicolumn{2}{|c|}{ Dias } \\
\hline TRAT. & 15 & 22 & 15 & 22 & 15 & 22 \\
\hline CONTROLE & $9,54 a b$ & $0,60 a$ & 9,31 a & $13,86 \mathrm{a}$ & $0,36 \mathrm{ab}$ & $0,09 a$ \\
\hline D-955 & $5,85 \quad b$ & $0,81 a$ & 8,41 a & $12,87 \mathrm{a}$ & $0,43 a b$ & $0,11 a$ \\
\hline PD-941 & $9,66 a b$ & $0,83 a$ & 8,41 a & $12,30 \mathrm{a}$ & $0,37 a b$ & $0,10 a$ \\
\hline PP PERF. & $8,59 a b$ & $0,87 a$ & 9,51 a & $13,74 a$ & $0,41 a b$ & $0,08 a$ \\
\hline CERA A $1: 1$ & $10,65 a$ & $0,60 \mathrm{a}$ & 8,77 a & $12,61 \mathrm{a}$ & $0,40 a b$ & $0,10 a$ \\
\hline CERA A $1: 3$ & $10,56 a$ & $0,51 \mathrm{a}$ & 9,27 a & $12,16 \mathrm{a}$ & $0,48 a$ & $0,07 a$ \\
\hline CERA B $1: 1$ & $10,76 a$ & $0,81 \mathrm{a}$ & $9,50 a$ & $13,23 a$ & $0,42 a b$ & $0,13 a$ \\
\hline CERA B 1:3 & $9,77 a b$ & $0,67 a$ & 9,04 a & $12,64 \mathrm{a}$ & $0,44 \mathrm{a}$ & $0,11 a$ \\
\hline REC. $1: 1$ & $8,37 a b$ & $0,69 a$ & 9,30 a & $13,05 \mathrm{a}$ & $0,28 \quad b$ & $0,15 a$ \\
\hline REC. $1: 3$ & $9,95 a b$ & $0,72 a$ & 9,43 a & $13,43 \mathrm{a}$ & $0,41 a b$ & $0,14 a$ \\
\hline F. & $2,27^{*}$ & $1,20 \mathrm{~ns}$ & $2,12^{\star}$ & $1,95 \mathrm{~ns}$ & $2,47^{*}$ & $1,95 \mathrm{~ns}$ \\
\hline DMS & 4,55 & 0,51 & 1,35 & 1,92 & 0,16 & 0,08 \\
\hline
\end{tabular}

ns, ${ }^{*}{ }^{* *}$ - Não significativo, significativo a $5 \%$ e a $1 \%$ de probabilidade, res pectivamente.

Valores, na coluna, seguidos pela mesma letra, não diferem entre si, estatisticamente, ao nivel de $5 \%$ de probabilidade. 
Tabela 4. Análises químicas e físicas de mangas 'Palmer' realizadas aos 21 dias de armazenamento a $12^{\circ} \mathrm{C}$ e após transferência por 8 dias (29 dias) a $25^{\circ} \mathrm{C}$.

\begin{tabular}{|c|c|c|c|c|c|c|c|}
\hline \multirow[b]{3}{*}{ TRAT. } & \multicolumn{3}{|c|}{ pH } & \multicolumn{2}{|c|}{ Cor da Casca } & \multicolumn{2}{|c|}{ Cor da Polpa } \\
\hline & \multicolumn{3}{|c|}{ Dias } & \multicolumn{2}{|c|}{ Dias } & \multicolumn{2}{|c|}{ Dias } \\
\hline & 21 & \multicolumn{2}{|l|}{29} & 21 & 29 & 21 & 29 \\
\hline CONTROLE & $3,65 \quad b$ & \multicolumn{2}{|c|}{$5,01 a b$} & $2,50 a$ & $4,29 a$ & $1,57 \mathrm{a}$ & $4,50 \mathrm{a}$ \\
\hline D-955 & $3,64 \quad b$ & 4,52 & $\mathrm{~cd}$ & $1,71 \mathrm{a}$ & $3,07 \quad \mathrm{~cd}$ & $2,21 \mathrm{a}$ & $4,11 \mathrm{a}$ \\
\hline PD-941 & $3,93 a$ & \multicolumn{2}{|c|}{$4,78 \quad b c$} & 1,79 a & $3,71 a b c$ & $1,29 a$ & $4,46 a$ \\
\hline PP PERF. & $3,50 \quad b$ & \multicolumn{2}{|c|}{4,69 bc } & $2,21 \mathrm{a}$ & $4,21 a b$ & $1,93 a$ & 3,82 a \\
\hline CERA A $1: 1$ & $3,60 \quad b$ & \multicolumn{2}{|c|}{$4,76 \quad b c$} & $2,50 a$ & $4,14 a b$ & $1,93 a$ & $4,14 a$ \\
\hline CERA A $1: 3$ & $3,73 a b$ & $4,1, \quad \mathrm{DC}$ & bc & $2,36 a$ & $4,07 \mathrm{ab}$ & $2,07 a$ & $4,36 a$ \\
\hline CERA B $1: 1$ & $3,63 \quad b$ & \multicolumn{2}{|c|}{$5,03 a b$} & $2,21 a$ & $3,36 \mathrm{bcd}$ & $1,57 a$ & $2,36 \quad b$ \\
\hline CERA B $1: 3$ & $3,73 a b$ & \multicolumn{2}{|c|}{4,81 bc } & $1,79 a$ & $3,36 \mathrm{bcd}$ & 2,07 a & $4,04 \mathrm{a}$ \\
\hline REC. $1: 1$ & $3,70 a b$ & 4,20 & $d$ & $2,14 a$ & $2,64 \quad d$ & $1,57 \mathrm{a}$ & $1,79 b$ \\
\hline REC. $1: 3$ & $3,76 \mathrm{ab}$ & \multicolumn{2}{|l|}{$5,27 \mathrm{a}$} & $2,57 a$ & $4,07 \mathrm{ab}$ & $1,86 a$ & $4,00 a$ \\
\hline F. & $4,25^{\star *}$ & \multicolumn{2}{|l|}{$14,89^{* *}$} & $1,68 \mathrm{~ns}$ & $8,07^{* *}$ & $1,88 \mathrm{~ns}$ & $19,56^{* *}$ \\
\hline \multirow[t]{3}{*}{ DMS } & 0,26 & \multicolumn{2}{|l|}{0,35} & 1,15 & 0,92 & 0,99 & 0,97 \\
\hline & \multicolumn{3}{|c|}{ Textura $(\mathrm{Kg})$} & \multicolumn{2}{|c|}{ Sól. Sol. $\left({ }^{\circ}\right.$ brix $)$} & \multicolumn{2}{|c|}{ Acidez Total } \\
\hline & \multicolumn{3}{|c|}{ Dias } & \multicolumn{2}{|c|}{ Dias } & \multicolumn{2}{|c|}{ Dias } \\
\hline TRAT. & 21 & \multicolumn{2}{|c|}{29} & 21 & 29 & 21 & 29 \\
\hline CONTROLE & $8,36 a$ & \multicolumn{2}{|c|}{$3,61 \mathrm{a}$} & $11,36 \mathrm{ab}$ & $14,31 \mathrm{a}$ & $0,45 a$ & $0,07 \quad b$ \\
\hline D-955 & $4,61 \mathrm{a}$ & 0,55 & $b$ & $10,69 \quad b c$ & 12,64 bc & $0,32 a$ & $0,08 \quad b$ \\
\hline PD-941 & $4,80 \mathrm{a}$ & 0,50 & $\mathrm{~b}$ & 10,01 & $12,74 a b c$ & $0,36 a$ & $0,08 \quad b$ \\
\hline PP PERF. & $6,69 a$ & 0,57 & $b$ & $12,31 a$ & $12,83 a b c$ & $0,42 a$ & $0,07 \quad b$ \\
\hline CERA A $1: 1$ & $6,38 a$ & 0,50 & $b$ & 11,27 abc & $13,13 a b c$ & $0,48 a$ & $0,08 \quad b$ \\
\hline CERA A $1: 3$ & 6,52 a & 0,50 & $b$ & $11,47 a b$ & $13,50 \mathrm{abc}$ & $0,39 a$ & $0,06 \quad b$ \\
\hline CERA B $1: 1$ & $9,84 a$ & 0,51 & $b$ & $12,09 a$ & $13,37 a b c$ & $0,45 a$ & $0,06 \mathrm{~b}$ \\
\hline CERA B $1: 3$ & 9,07 a & 0,50 & $b$ & $12,21 a$ & $13,54 a b c$ & $0,42 a$ & $0,07 \quad b$ \\
\hline REC. $1: 1$ & $8,32 a$ & 0,74 & $\mathrm{~b}$ & $11,20 a b c$ & $11,96 \quad c$ & $0,37 a$ & $0,20 a$ \\
\hline REC. $1: 3$ & $9,91 \mathrm{a}$ & 0,50 & $\mathrm{~b}$ & $12,44 a$ & $14,04 \mathrm{ab}$ & $0,40 a$ & $0,05 \mathrm{~b}$ \\
\hline F. & $2,49^{*}$ & $6,39^{*}$ & & $7,67^{\star \star}$ & $3,95^{\star *}$ & 1,72 ns & $23,67^{\star *}$ \\
\hline DMS & 5,70 & 1,79 & & 1,30 & 1,63 & 0,16 & 0,04 \\
\hline
\end{tabular}

ns, ${ }^{*},{ }^{* *}$ - Não significativo, significativo a $5 \%$ e a $1 \%$ de probabilidade, respectivamente.

Valores, na coluna, seguidos pela mesma letra, não diferem entre si, estatisticamente, ao nivel de $5 \%$ de probabilidade. 
Tabela 5. Análises químicas e físicas de mangas 'Palmer' realizadas aos 28 dias de armazenamento a $12^{\circ} \mathrm{C}$ e após 6 dias (34 dias) da transferência para $25^{\circ} \mathrm{C}$.

\begin{tabular}{|c|c|c|c|c|c|c|}
\hline \multirow[b]{3}{*}{ TRAT. } & \multicolumn{2}{|c|}{$\mathrm{pH}$} & \multicolumn{2}{|c|}{ cor da casca } & \multicolumn{2}{|c|}{ Cor da Polpa } \\
\hline & \multicolumn{2}{|c|}{ Dias } & \multicolumn{2}{|c|}{ Dias } & \multicolumn{2}{|c|}{ Dias } \\
\hline & 28 & 34 & 28 & \multirow{2}{*}{$\frac{34}{4,71 \mathrm{a}}$} & \multirow{2}{*}{$\frac{28}{2,18 a}$} & \multirow{2}{*}{$\frac{34}{3,07 \mathrm{a}}$} \\
\hline CONTROLE & $3,60 \quad b$ & $4,81 a$ & $2,93 \mathrm{abc}$ & & & \\
\hline D-955 & $3,73 a b$ & $4,80 a$ & 1,43 & $3,50 \quad b c$ & $1,57 \mathrm{a}$ & $3,21 \mathrm{a}$ \\
\hline PD-941 & $3,91 \mathrm{a}$ & $4,95 a$ & 2,00 & $3,93 \mathrm{abc}$ & $1,46 a$ & $3,36 \mathrm{a}$ \\
\hline PP PERF. & 3,86 a & $5,08 a$ & $2,79 \mathrm{abc}$ & $4,43 a b$ & $2,29 a$ & $3,50 \mathrm{a}$ \\
\hline CERA A $1: 1$ & $3,55 \quad b$ & 4,86 a & $3,00 \mathrm{abc}$ & $3,07 \quad c$ & $1,79 a$ & $3,00 \mathrm{a}$ \\
\hline CERA A $1: 3$ & $3,76 a b$ & $5,13 a$ & $3,21 \mathrm{ab}$ & $4,07 a b$ & $2,14 a$ & $2,96 a$ \\
\hline CERA B $1: 1$ & $3,70 a b$ & $4,74 a$ & $2,71 \mathrm{abc}$ & $3,64 \mathrm{bc}$ & $2,07 a$ & $3,29 a$ \\
\hline CERA B $1: 3$ & $3,69 a b$ & $5,13 a$ & $3,36 a$ & $4,00 \mathrm{abc}$ & $2,07 a$ & $3,64 a$ \\
\hline REC. $1: 1$ & $3,72 a b$ & $4,70 \mathrm{a}$ & $1,86 \quad \mathrm{~cd}$ & $3,07 \quad c$ & $2,00 a$ & $2,93 a$ \\
\hline REC. $1: 3$ & $3,87 \mathrm{a}$ & $5,08 \mathrm{a}$ & 2,14 bcd & 4,00 abc & $2,21 \mathrm{a}$ & $3,29 \mathrm{a}$ \\
\hline F. & $5,97^{\star \star}$ & $2,39^{*}$ & $6,49^{\star \star}$ & $6,69^{\star \star}$ & $1,83 \mathrm{~ns}$ & $1,04 \mathrm{~ns}$ \\
\hline \multirow[t]{3}{*}{ DMS } & 0,22 & 0,50 & 1,17 & 0,96 & 0,96 & 1,08 \\
\hline & \multicolumn{2}{|c|}{ Textura $(\mathrm{Kg})$} & \multicolumn{2}{|c|}{ Sól. Sol. $\left({ }^{\circ} \mathrm{Brix}\right)$} & \multicolumn{2}{|c|}{ Acidez Total } \\
\hline & \multicolumn{2}{|c|}{ Dias } & \multicolumn{2}{|c|}{ Dias } & \multicolumn{2}{|c|}{ Dias } \\
\hline TRAT. & 28 & 34 & 28 & 34 & 28 & 34 \\
\hline CONTROLE & $4,74 a$ & $0,66 a$ & $12,51 \mathrm{ab}$ & $13,91 \mathrm{a}$ & $0,41 \quad c$ & $0,07 \quad b$ \\
\hline D-955 & $3,86 a$ & $0,50 a$ & $9,14 \quad \mathrm{~d}$ & $12,14 \quad b$ & 0,30 & $0,10 a b$ \\
\hline PD-941 & $4,75 a$ & $0,50 a$ & $10,29 \mathrm{~cd}$ & $13,51 \mathrm{ab}$ & $0,39 \quad c$ & $0,08 \quad b$ \\
\hline PP PERF. & $5,27 a$ & $0,54 a$ & $12,09 a b$ & $12,63 a b$ & $0,52 \mathrm{bc}$ & $0,08 \quad b$ \\
\hline CERA A $1: 1$ & $5,79 a$ & $0,50 a$ & $11,51 \quad b c$ & $12,50 a b$ & $0,45 \mathrm{bc}$ & $0,11 a b$ \\
\hline CERA A $1: 3$ & $4,59 a$ & $0,52 a$ & $12,81 a b$ & $13,84 a b$ & $0,70 a b$ & $0,09 a b$ \\
\hline CERA B $1: 1$ & $7,01 \mathrm{a}$ & $1,03 a$ & $12,54 a b$ & $13,71 a b$ & 0,46 bc & $0,13 a b$ \\
\hline CERA B $1: 3$ & $5,64 a$ & $0,54 a$ & $13,29 a$ & $13,96 \mathrm{a}$ & $0,39 \quad c$ & $0,10 a b$ \\
\hline REC. $1: 1$ & $3,75 \mathrm{a}$ & $0,51 \mathrm{a}$ & $11,96 a b$ & $13,20 a b$ & 0,29 & $0,15 a$ \\
\hline REC. $1: 3$ & $2,26 \mathrm{a}$ & $0,51 \mathrm{a}$ & $12,54 \mathrm{ab}$ & $13,31 \mathrm{ab}$ & $0,84 a$ & $0,09 a b$ \\
\hline F. & $1,48 \mathrm{~ns}$ & $1,72 \mathrm{~ns}$ & $14,70^{\star \star}$ & $3,09^{\star \star}$ & $9,33^{\star \star}$ & $3,10^{\star \star}$ \\
\hline DMS & 4,99 & 0,58 & 1,53 & 1,71 & 0,26 & 0,07 \\
\hline
\end{tabular}

ns, * ${ }^{*}$ - Não significativo, significativo a $5 \%$ a a $1 \%$ de probabilidade, res pectivamente.

Valores, na coluna, seguidos pela mesma letra, não diferem entre si, estatisticamente, ao nivel de $5 \%$ de probabilidade. 


\section{b) Cor da casca}

Os dados sobre a evolução da cor da casca dos frutos sob armazenagem frigorífica e submetidos aos diferentes tratamentos encontram-se na Figura 2 (A) e Tabela 2, onde se visualiza na Figura 2 (A) uma tendência de aumento no decorrer do periodo em que as mangas estiveram sob estas condições. Os tratamentos D-955, PD-941 e PP PERF. apresentam uma evolução mais retardada que a do controle, embora somente o filme plástico D955 tenha demostrado diferença estatística. Resultados semelhantes obteve Ramos (1994) em mangas dos cvs. Parvin, Keitt e Tommy Atkins submetidas a tratamentos com cera e plástico, mantidas a temperatura de $14^{\circ} \mathrm{C}$ e $77 \%$ de UR. O tratamento REC. 1:1 apresenta evolução da coloração da casca até os 15 dias de armazenamento para em seguida ir declinando até o final do período em questão, indicando que houve a retenção da clorofila em conseqüência da redução da taxa respiratória e diminuição na produção de etileno $\left(\mathrm{C}_{2} \mathrm{H}_{4}\right)$, de acordo com o descrito por Kader et al. (1989).

Quando as mangas foram transferidas para as condições controladas o processo de evolução da cor foi mais intenso (Figura 2 (B), (C) e (D)), comparando-se com resultados encontrados por Ramos (1994), Seymor et al. (1990) e Medlicott et al. (1990b), onde verificaram uma aceleração no desenvolvimento da cor da casca das mangas utilizadas em seus estudos, ao colocá-las sob condições ambientais $\left(23\right.$ a $\left.25^{\circ} \mathrm{C}\right)$, depois de armazenadas em câmaras frigorificas $\left(12\right.$ a $\left.14^{\circ} \mathrm{C}\right)$. Percebe-se que o tratamento REC. $1: 1$, não permitiu que a cor da casca evoluisse normalmente quando foram transferidas para as condições controladas, assim acontecendo com o tratamento REC 1:3 aos 22 dias e CERA A 1:1 aos 34 dias.

Os frutos embalados nos filmes plásticos D-955, PD-941 e PP PERF. tiveram um desenvolvimento da cor da casca comparável ao do controle, sem expressarem diferença estatística significativa, quando 


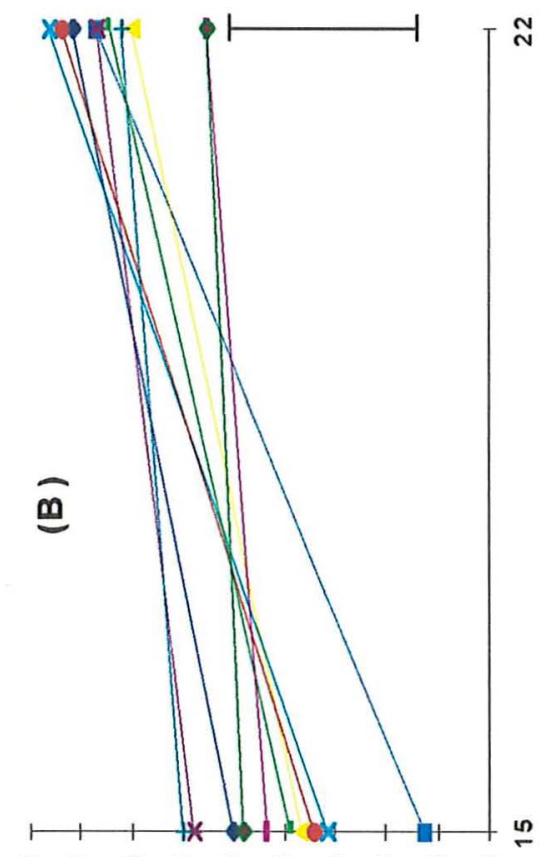

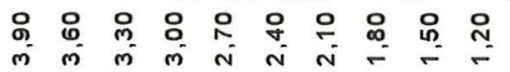

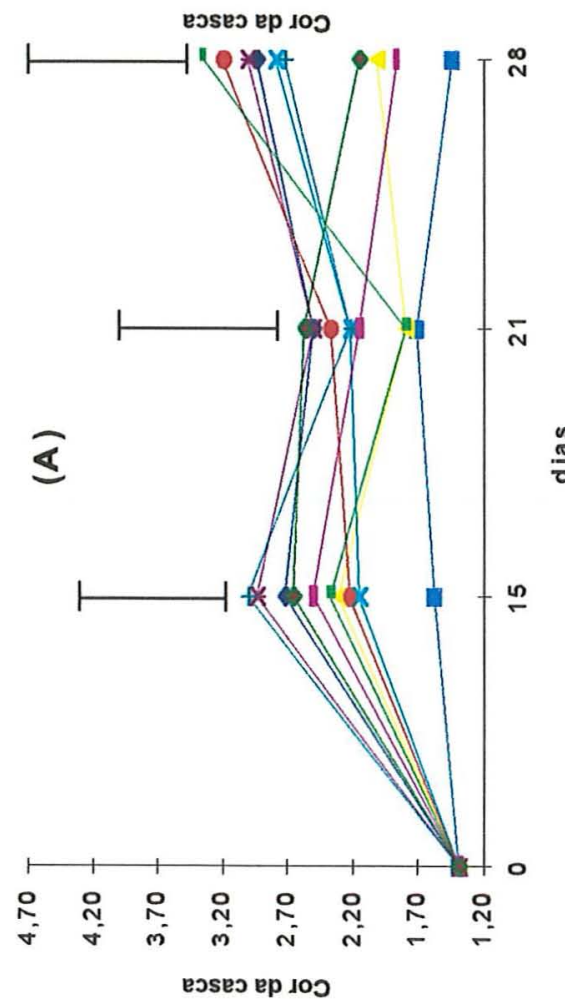

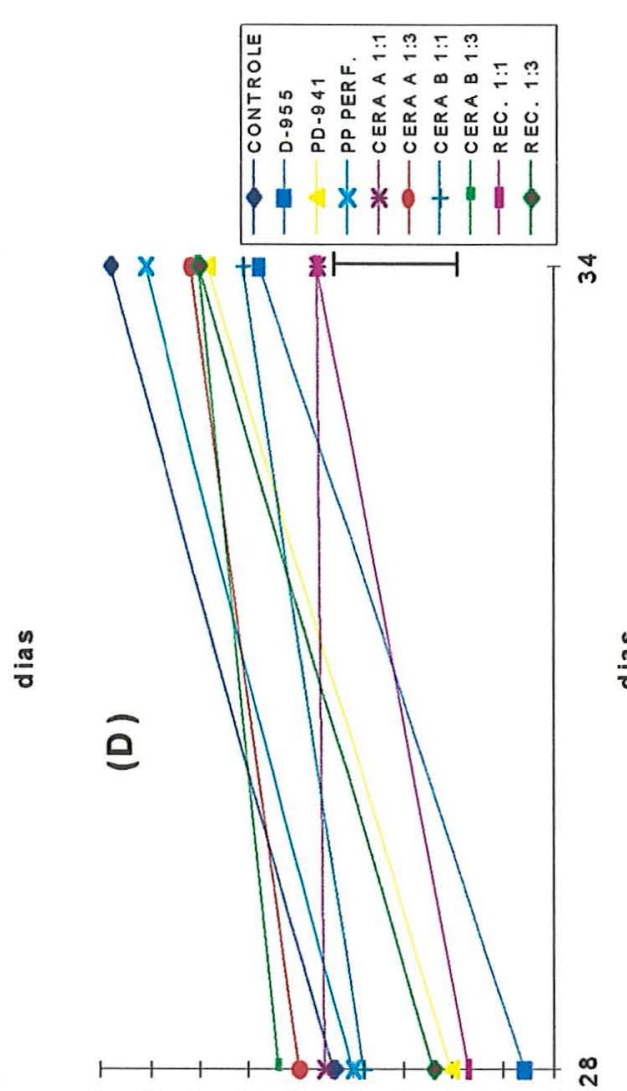

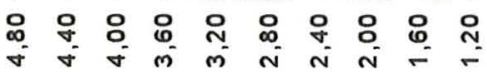

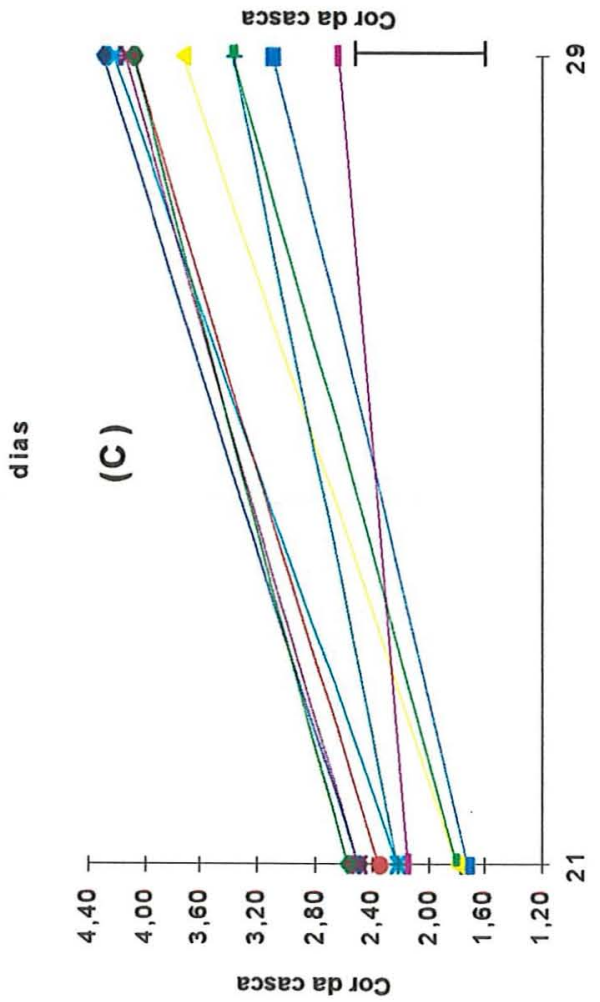

흐

응 음

ֻ

○ $1 \frac{9}{0}$

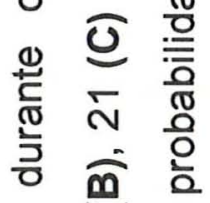

ขึ $\frac{10}{5} 8$

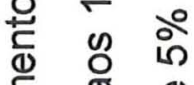

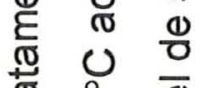

$\stackrel{\text { ๓) }}{\frac{\pi}{8}}$

닌 $\stackrel{\circ}{\stackrel{0}{\circ}}$

幽

(1)

产

(1)

ชั

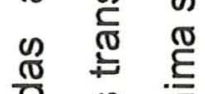

을

के

产 $\stackrel{0}{\frac{0}{4}}$

ह 0 व

@ั

(5)

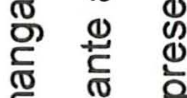

$\frac{\pi}{7}$

ฮ

응

질

४

ठु $\frac{E}{\sigma}$ त

व

ठั है त

ठ ำ

i

뜬 
transferidos para as condições controladas após 15 dias de armazenamento sob refrigeração (Figura 2 (B) e Tabela 3). Já aos 21 e 28 dias (Figura (C) e (D) e Tabelas 4 e 5) somente o filme plástico D-955 mostrou diferença estatística, com coloração inferior ao controle.

\section{c) Cor da polpa}

Os tratamentos a que foram submetidos os frutos armazenados sob refrigeração, não causaram efeito significativo ao nível de $5 \%$ de probabilidade, quanto ao desenvolvimento da cor da polpa (Figura 3 (A) e Tabela 2).

A cor da polpa evoluiu normalmente quando os frutos foram colocados em condições controladas, não apresentando diferença estatística entre a maioria dos tratamentos, porém os tratamentos REC. 1:1 na transferência aos 15 e 21 dias e CERA B 1:1 aos 21 dias, causaram um efeito prejudicial quanto a evolução deste parâmetro (Figura 3 (B), (C) e (D) e Tabelas 3,4 e 5).

Seymor et al (1990) e Medlicott et al. (1990b), mostraram resultados semelhantes, quando submeteram mangas colhidas no estádio "de vez" dos cvs. Amelie, Keitt e Tommy Atkins a temperaturas de $12^{\circ} \mathrm{C}$ que depois foram transferidas para câmaras sob temperatura de 23 a $25^{\circ} \mathrm{C}$. Os frutos tiveram uma evolução da coloração durante o período de armazenamento a temperaturas mais altas, depois de ter apresentado retenção sob condições refrigeradas.

\section{d) Textura}

As mudanças ocorridas na textura dos frutos expressas na Figura 4 (A) e Tabela 2, referem-se ao período em que estiveram sob efeito dos 


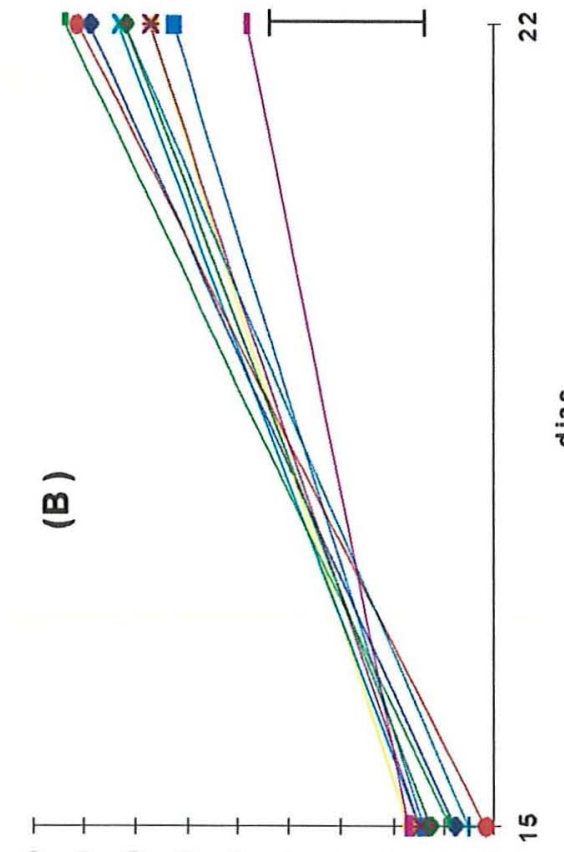

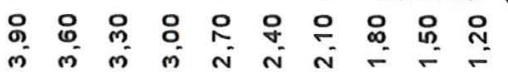
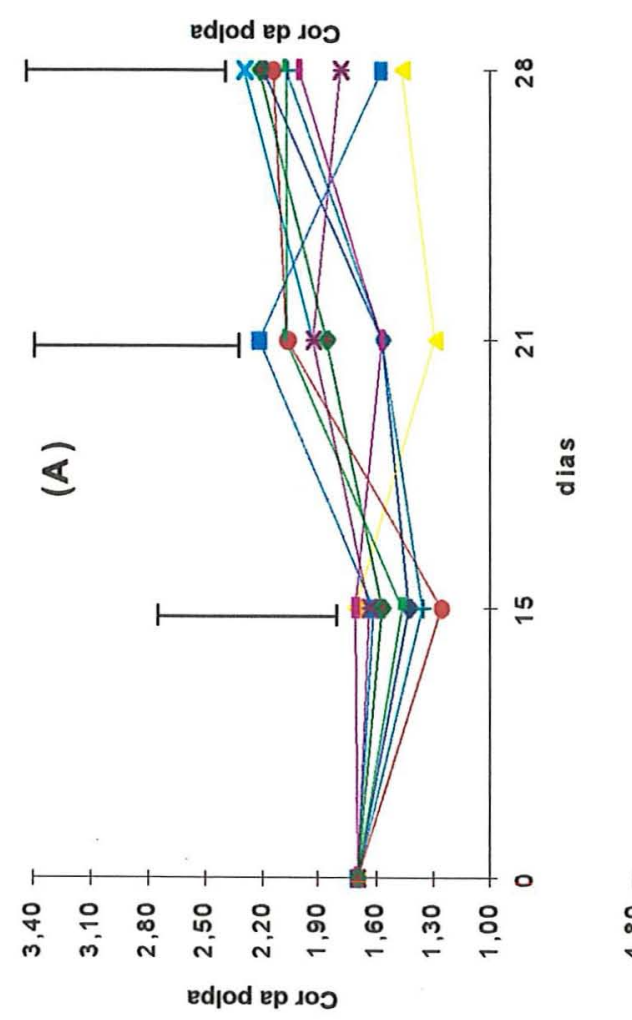

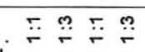

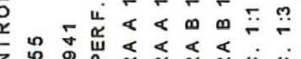

等

1 $1 x * 1+11$

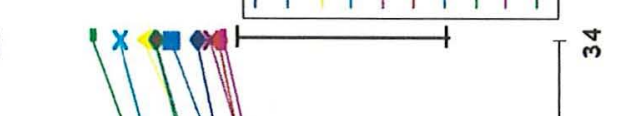

$\stackrel{\frac{\pi}{6}}{\frac{\pi}{0}}$

a

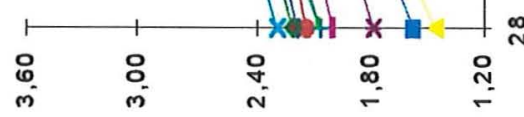

edjod ep 100

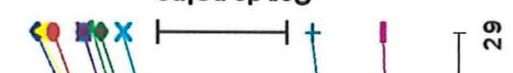

음

음 윰

¿ัญ

- $10 \frac{\Phi}{0}$

늘 으

진

ว

ஸึ ณ

대

ह

$\stackrel{n}{\frac{\pi}{8}}$

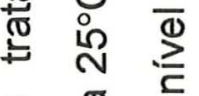

๘

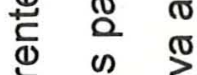

这 范

の 这

ชั 兵 高

क त

휼

들 을 ญ

() 0 ब

닌

ह $U$ त

ㅁํㄴ

(1) 1 芒

ชั ญ ญ

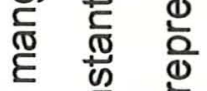

๑ 응

- 0

을 율

을 ह

(든

ठ

ঠั

लं

뜐 


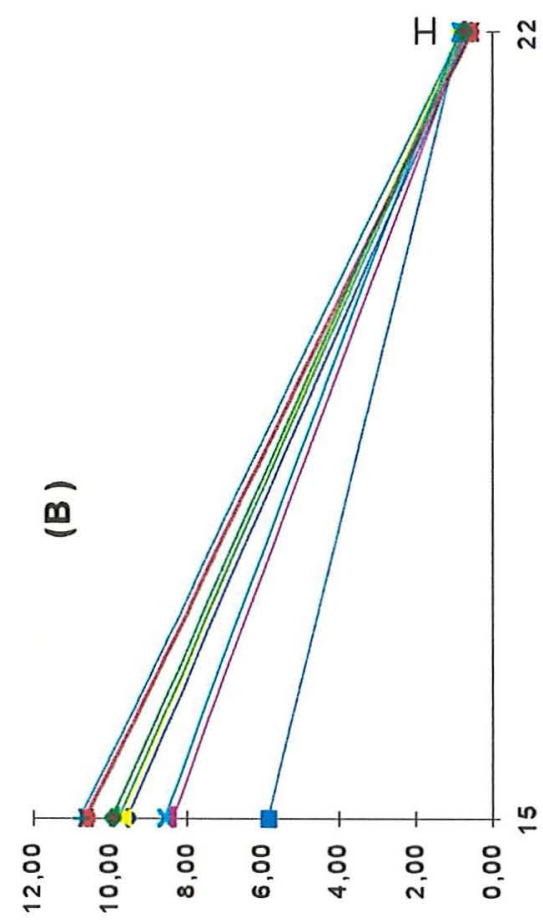

(6)्र) Eมnวхә।

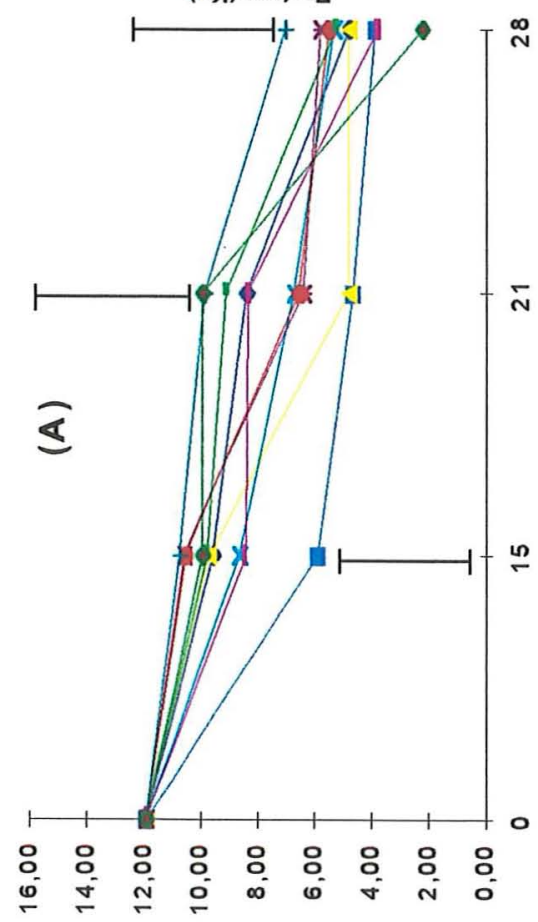

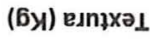

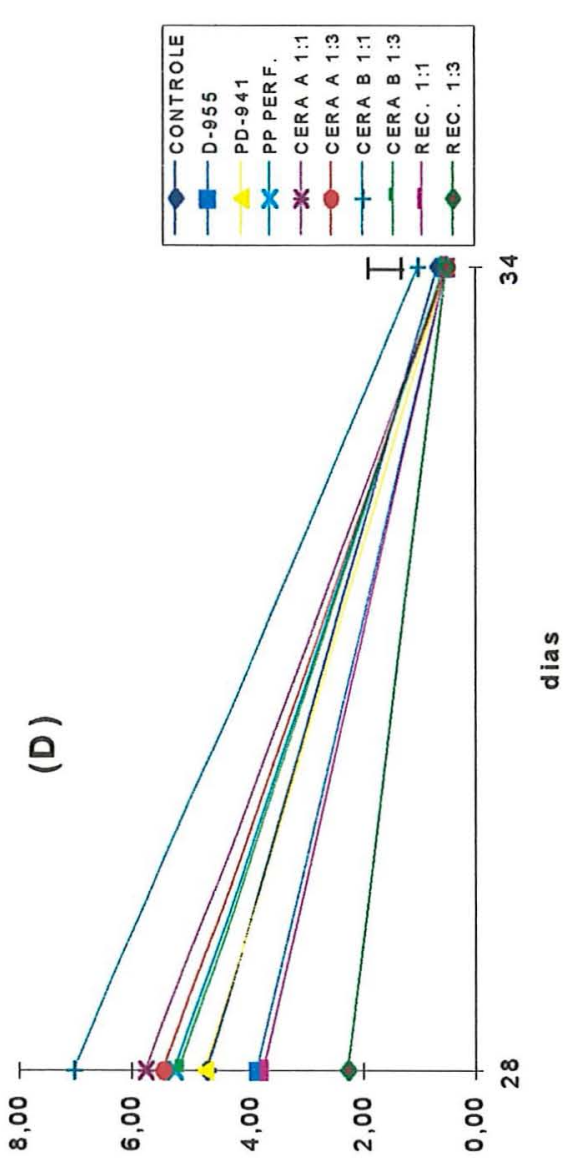

(6)्र) องกฺฺxə।

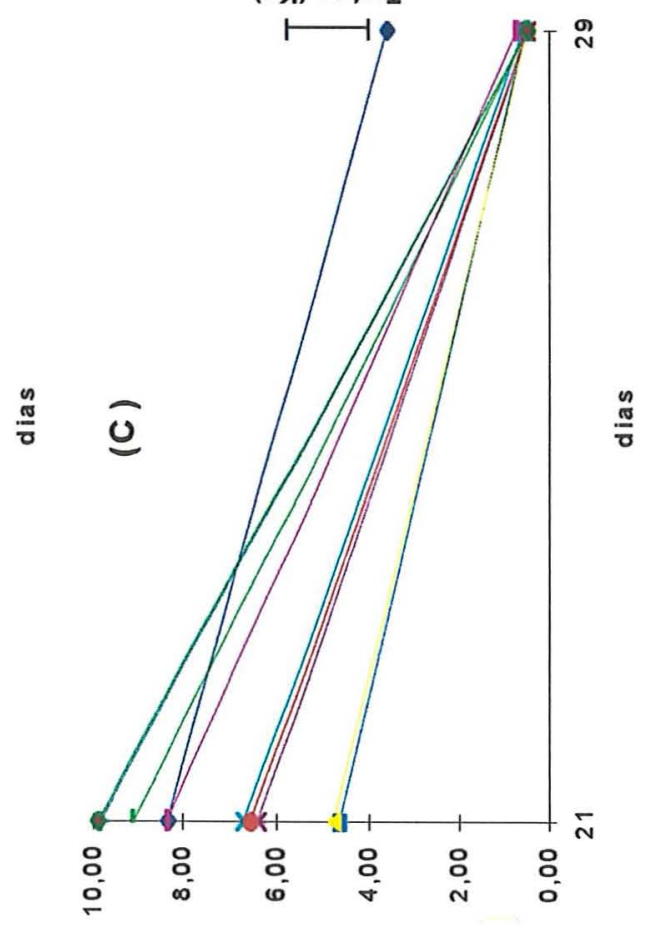

(6) อ.กฤฺญอ।

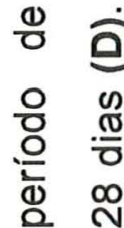

ㅇํ ๖

- $0 \frac{7}{0}$

冚

ตั

亭 吕

苞 0

혼

ฮ तั

劳

旁

ก

(1)

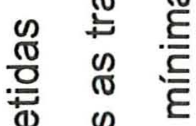

कํํㄹ 응

눤

E 00

ก $\stackrel{\circ}{\circ}$

(2) 0 ह

苋

Е

๑ 0 \%

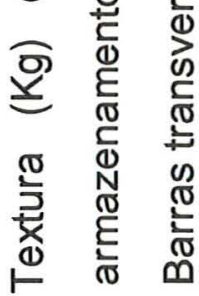

$\dot{\nabla}$

뜬 
tratamentos e mantidos em câmara frigorífica, onde houve uma tendência constante de diminuição, muito embora a queda se dê de maneira mais suave que a observada nas Figuras 4. (B), (C) e (D), referentes aos tratamentos transferidos para condições controladas. As análises estatísticas dos dados obtidos dos frutos submetidos às condições de refrigeração não detectaram diferença entre os tratamentos e o controle. Camillo-Lopez et al. (1995), ao tratarem frutos do cv. Keitt com varias concentrações da cera "Semperfresh" $(0$, $0,7 \%, 1,4 \%$ e $2,1 \%)$ sob refrigeração $\left(13^{\circ} \mathrm{C}\right)$, perceberam que os tratamentos não retardaram o amolecimento dos frutos. Miller et al.(1983) relataram os mesmos resultados, quando embalaram mangas 'Tommy Atkins' em filmes plásticos termo-encolhíveis, durante 14 dias a temperatura de $12^{\circ} \mathrm{C}$.

Os resultados encontrados nos frutos transferidos para as condições controladas (Figura 4 (B), (C) e (D) e Tabelas 3, 4 e 5) demostram que a textura das mangas submetidas aos diferentes tratamentos tende a diminuir progressivamente no decorrer do amadurecimento do fruto, sem contudo diferir estatisticamente em relação ao controle, a não ser na transferência realizada aos 21 dias (Figura $4(C)$ ), onde o controle apresenta uma firmeza bem superior, causada pela presença de três frutos, dos sete analisados, que não desenvolveram normalmente 0 processo de amadurecimento, elevando a média no resultado final.

O desenvolvimento do amolecimento dos frutos tem sido interpretado como uma mudança nos materiais pectínicos que cimentam a parede celular e é caracterizado pela solubilização de substâncias pécticas da lamela média (Medlicott, 1985 e Roe \& Bruemmer, 1981). Kapse et al. (1988), verificaram em seu trabalho que o desenvolvimento do amolecimento foi relacionado com a degradação de substâncias pécticas, em mangas das variedades Malda e Malgoa, sendo mais acelerado quando os frutos foram armazenados a temperatura ambiente $\left(25\right.$ a $\left.30^{\circ} \mathrm{C}\right)$ que a baixa temperatura (10 $\pm 1^{\circ} \mathrm{C}$ ), onde a taxa de conversão foi mais lenta. 


\section{e) Sólidos solúveis}

O teor de sólidos solúveis expressos em ${ }^{\circ}$ Brix, sofreu uma evolução progressiva (Figura 5 (A) e Tabela 2), durante todo o tempo em que os frutos dos diferentes tratamentos estiveram sob condições de refrigeração. Nota-se que os filmes plásticos PD-941 e o D-955 proporcionaram retardamento no desenvolvimento dos sólidos solúveis e que aos 21 e aos 28 dias do início do armazenamento foi detectada diferença estatística significativa, a nível de $5 \%$ de probabilidade, em comparação com o controle. O filme plástico D-955 apresentou um declínio no teor de sólidos solúveis no decorrer do periodo de 21 a 28 dias, esta diminuição pode ter sido causada pela redução da conversão de amido em açúcares, devido as condições da atmosfera no interior da embalagem apresentarem reduzida taxa de $\mathrm{O}_{2}$ e elevada de $\mathrm{CO}_{2}$., conforme preconizado por Zagory \& Kader (1989). Das ceras utilizadas no tratamento dos frutos, a CERA A 1:1, também demonstrou uma menor evolução do parâmetro estudado, porém nenhuma significância foi constatada.

Os frutos transferidos para as condições controladas tiveram a evolução do teor de sólidos solúveis considerada normal, conforme dados da Figura 5 (B), (C) e (D) e Tabelas 3, 4 e 5, quando comparados aos encontrados por Camillo-Lopez et al. (1995), Ramos (1994) e Yamashita (1995) em mangas dos cvs. Haden, Parvin e Keitt, respectivamente. Somente nos tratamentos REC. $1: 1$ aos 29 dias (Figura 5 (C) e Tabela 3) e o D-955 aos 29 e 34 dias (Figura 5 (C) e (D) e Tabela 4 e 5) foi observado diferença estatística significativa em relação ao controle, evidenciando um menor teor de sólidos solúveis, sem contudo comprometer a qualidade dos frutos com respeito a este parâmetro, uma vez que Medlicott et al. (1988), considerou como de qualidade mangas 'Tommy Atkins' que mantiveram um teor acima de $9,5^{\circ}$ Brix, quando estudou esta cultivar em três estádios de maturação. 

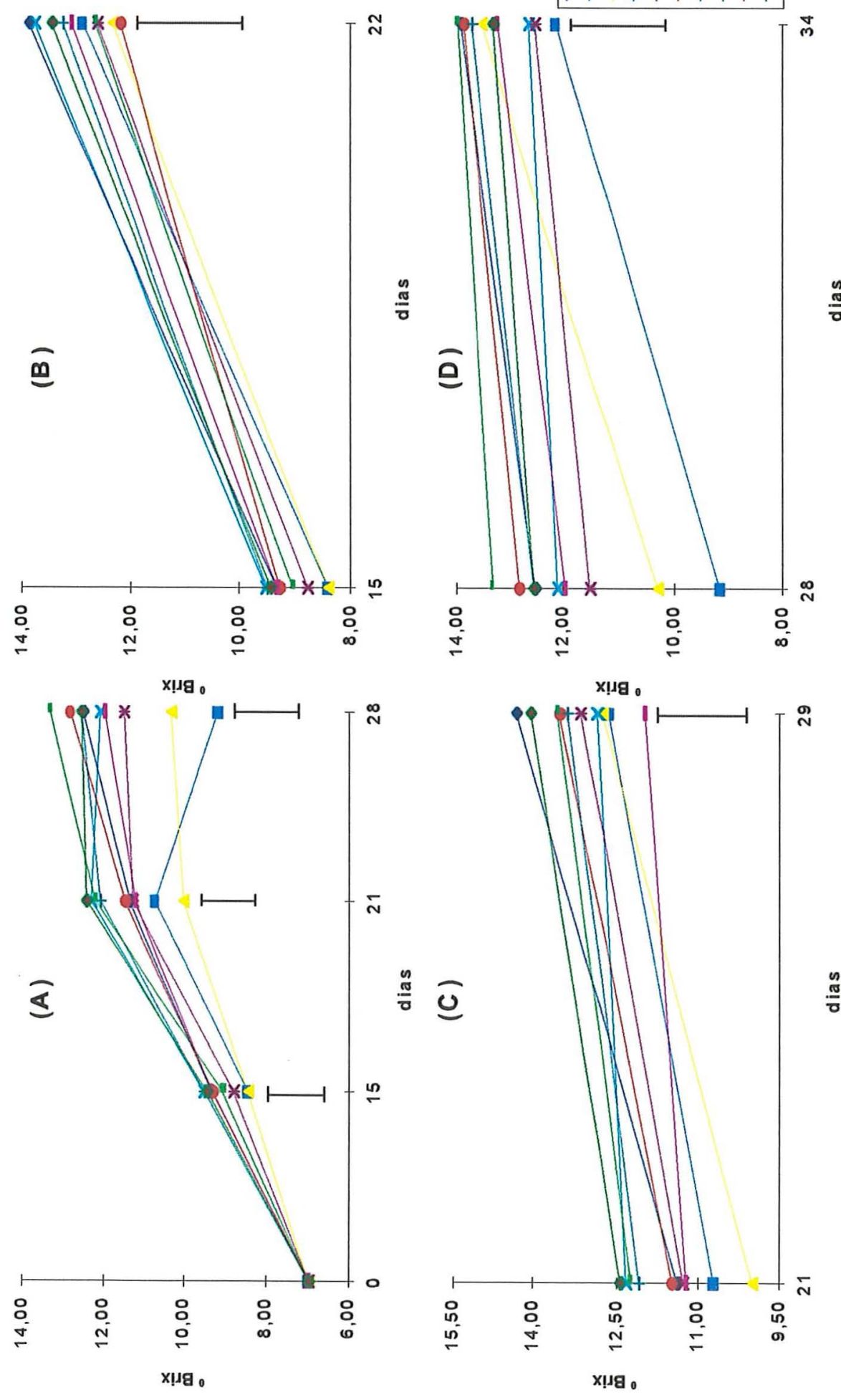

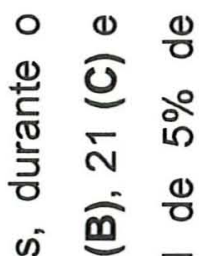

畩

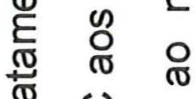

तै 0

แ ำ ำ

选 ত

产 @

$\stackrel{9}{0}$

(1)

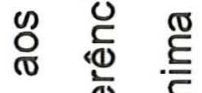

๗

음 윤

है

= 只 売

ฮ

त $\frac{E}{\square}$

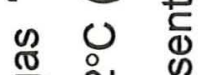

으 ஸ

흐 ㅇํํ

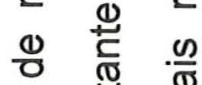

즌 듕

ஸे ठ ल

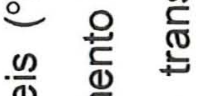

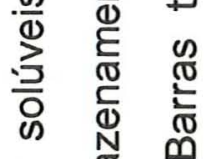

๓) ญี

응 등

() $\frac{0}{0}$

잉 음 뜽

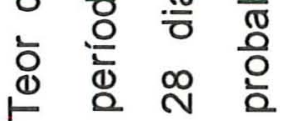

in

흔 


\section{f) Acidez total}

A acidez total dos frutos nos diferentes tratamentos submetidos às condições frigoríficas, teve tendência de diminuir no decorrer deste período de armazenamento (Figura 6 (A) e Tabela 2). Percebe-se, no entanto, que esse declínio não ocorre de maneira acentuada, indicando que houve uma retenção no metabolismo de transformação dos ácidos orgânicos pelo uso da refrigeração, uma vez que os tratamentos empregados não demostraram efeito significativo quanto a este aspecto. Estes resultados também foram observados por Kapse et al. (1988) e Ramos (1994) em mangas armazenadas a baixas temperaturas $\left(10 \pm 1^{\circ} \mathrm{C}\right.$ e $14,0^{\circ} \mathrm{C}$, respectivamente).

Sob condições controladas o metabolismo dos frutos se processa de maneira mais acentuada, onde se verifica uma diminuição mais rápida na acidez total (Figura 6 (B), (C) e (D) e Tabelas 3, 4 e 5). Ramos (1994) observou uma diminuição de $0,666 \mathrm{~g}$ de ác. cítrico/100 g de polpa para $0,09 \mathrm{~g}$ de ác. cítrico/100 g de polpa, durante o amadurecimento de mangas $\mathrm{cv}$. Tommy Atkins a temperatura ambiente $\left(25,6^{\circ} \mathrm{C}\right)$.

\subsection{Análises sensoriais das mangas embaladas com filmes plásticos, armazenadas por 21 e 28 dias a $12^{\circ} \mathrm{C}$ e após transferência por 8 dias (29 dias) e 6 dias ( 34 dias) respectivamente, para $25^{\circ} \mathrm{C}$.}

As mangas embaladas com filmes plásticos foram avaliadas quanto aos aspectos de odor, sabor e qualidade global, após armazenamento frigorifico por 21 e 28 dias e transferência para as condições controladas por 8 e por 6 dias, perfazendo um período total de 29 e 34 dias, respectivamente. Os dados encontrados foram submetidos a uma análise de variância e teste de Tukey para comparação entre médias, cujos resultados serão apresentados e discutidos nesta seção. 


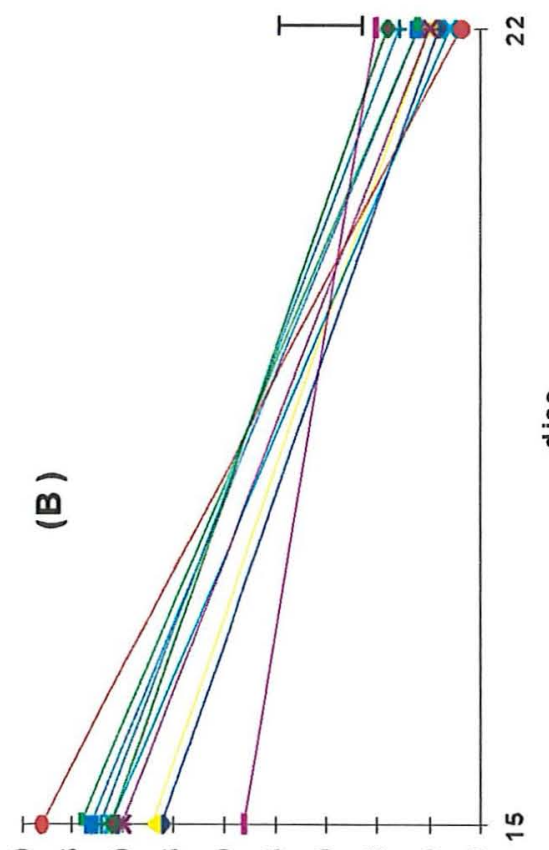

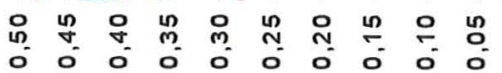

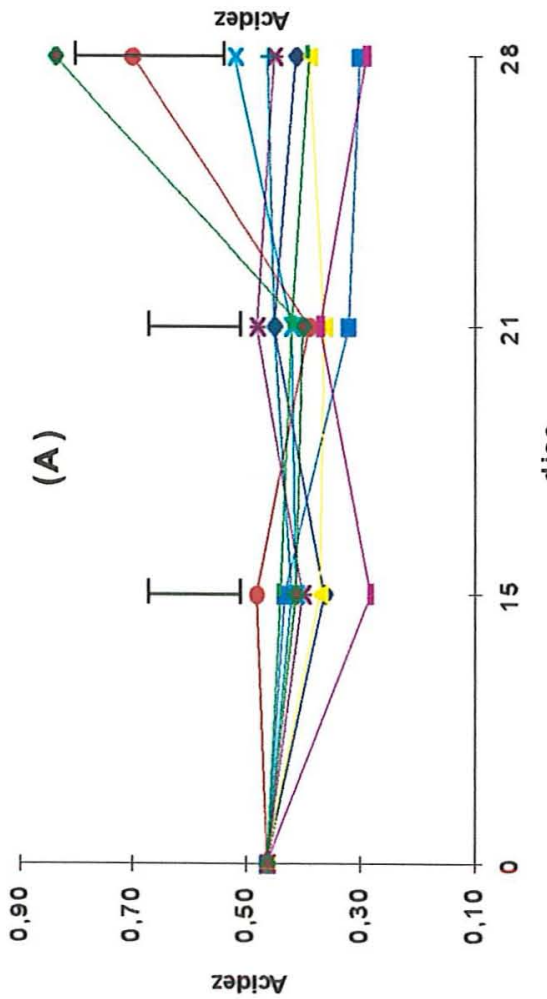

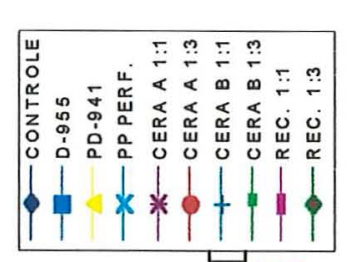
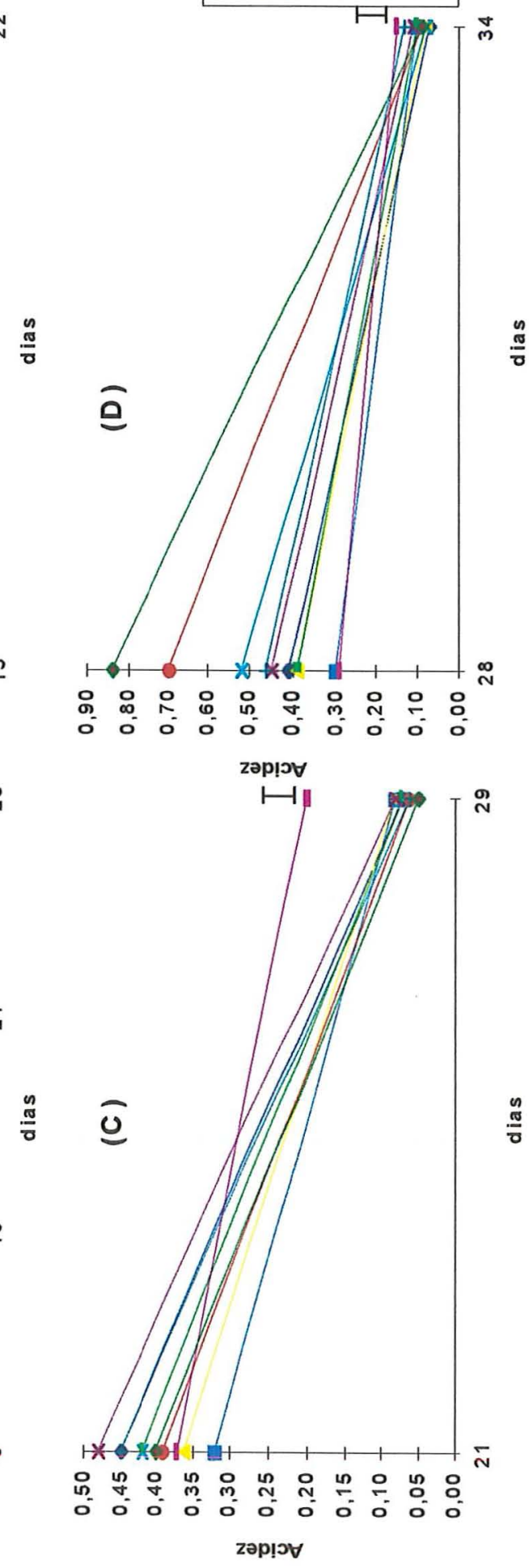

กิ

닌 운

㲾

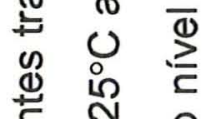

กั

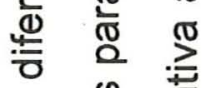

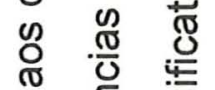

满

.

$\stackrel{\frac{\pi}{7}}{\frac{\pi}{2}}$

焉

¿

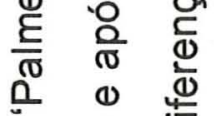

(1) $\widehat{\text { s }}$

व)

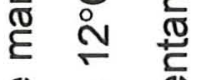

๑)

จ

응 焉 인

일

일

을

당

ํํㄴ

을

-

응 응

이 은 음

ब ळ

N

는 冚 స 응

ம

竞 
Os frutos embalados em filmes plásticos e armazenados até os 29 dias não diferiram estatisticamente com relação ao desenvolvimento do sabor $e$ odor, vindo a manifestar diferença quanto ao aspecto de qualidade global, onde se verifica que o tratamento D-955 mostrou diferença em relação ao controle, mas teve comportamento igual aos demais filmes plásticos (Tabela $6)$.

Tabela 6. Análise sensorial de mangas 'Palmer' armazenadas por 21 dias a $12^{\circ} \mathrm{C}$ e após transferência por 8 dias (29 dias) para $25^{\circ} \mathrm{C}$.

\begin{tabular}{|c|c|c|c|c|c|c|}
\hline \multirow[b]{2}{*}{ TRAT. } & \multicolumn{2}{|c|}{ ODOR } & \multicolumn{3}{|c|}{$\overline{\text { SABOR }}$} & \multirow[t]{2}{*}{ Q. GLOBAL } \\
\hline & CARACT. & ESTRANHO & CARACT. & FERMENT. & ÁCIDO & \\
\hline CONTROLE & $6,44 a$ & $1,00 \mathrm{a}$ & $6,22 a$ & $1,67 \mathrm{a}$ & $1,56 a$ & $6,44 \mathrm{~b}$ \\
\hline PD-941 & $6,78 \mathrm{a}$ & $1,00 \mathrm{a}$ & $6,67 a$ & $1,56 \mathrm{a}$ & $1,78 a$ & $7,22 a b$ \\
\hline PP PERF. & $6,56 a$ & $1,00 \mathrm{a}$ & $7,33 a$ & $1,00 \mathrm{a}$ & $1,33 a$ & $7,78 \mathrm{ab}$ \\
\hline D-955 & $6,44 \mathrm{a}$ & $1,11 \mathrm{a}$ & $7,33 \mathrm{a}$ & $1,11 \mathrm{a}$ & $1,44 \mathrm{a}$ & $8,00 \mathrm{a}$ \\
\hline $\begin{array}{l}\text { F. } \\
\text { DMS. }\end{array}$ & $\begin{array}{l}0,08 \mathrm{~ns} \\
2,17 \\
\end{array}$ & $\begin{array}{l}1,00 \mathrm{~ns} \\
0,21\end{array}$ & $\begin{array}{l}1,59 \mathrm{~ns} \\
1,65 \\
\end{array}$ & $\begin{array}{l}2,04 \text { ns } \\
0,88\end{array}$ & $\begin{array}{l}0,74 \text { ns } \\
0,85\end{array}$ & $\begin{array}{l}2,92^{*} \\
1,55\end{array}$ \\
\hline
\end{tabular}

A avaliação sensorial realizada nos frutos embalados e armazenados por 34 dias (Tabela 7) mostra que foi detectado um sabor fermentado nos frutos embalados em filmes plásticos PD-941 e D-955, mas somente o D-955 diferiu estatisticamente do PP PERF. que não desenvolveu este sabor. Quanto a qualidade global o filme PP PERF. obteve o melhor resultado, sendo detectado diferença estatística em relação aos demais tratamentos. O valor atribuído aos frutos considerados com sabor fermentado corresponde, na escala de notas utilizada, a um sabor ligeiro, não sendo suficiente portanto para ser detectado pelas análises físico-químicas 
realizadas. Os frutos do tratamento controle não foram suficientes, nesta época, para a realização destas análises.

Tabela 7. Análise sensorial de mangas 'Palmer' armazenadas por 28 dias a $12^{\circ} \mathrm{C}$ e após transferência por 6 dias (34 dias) para $25^{\circ} \mathrm{C}$.

\begin{tabular}{|c|c|c|c|c|c|c|}
\hline \multirow[b]{2}{*}{ TRAT. } & \multicolumn{2}{|c|}{ ODOR } & \multicolumn{3}{|c|}{ SABOR } & \multirow[t]{2}{*}{ Q. GLOBAL } \\
\hline & CARACT. & ESTRANHO & CARACT. & FERMENT. & ÁCIDO & \\
\hline PD-941 & $5,30 a$ & $1,90 a$ & $5,50 a$ & $2,20 a b$ & $1,70 a$ & $6,40 \quad b$ \\
\hline PP PERF. & $5,90 \mathrm{a}$ & $1,20 \mathrm{a}$ & $6,40 a$ & $1,10 \quad b$ & $1,70 a$ & $7,50 \mathrm{a}$ \\
\hline D-955 & $5,30 \mathrm{a}$ & $1,70 \mathrm{a}$ & $6,00 \mathrm{a}$ & $2,40 a$ & $2,50 a$ & $6,20 \quad b$ \\
\hline$\overline{\mathbf{F}}$. & $0,34 \mathrm{~ns}$ & $1,15 \mathrm{~ns}$ & $1,34 \mathrm{~ns}$ & $3,79^{\star}$ & $1,88 \mathrm{~ns}$ & $4,99^{\star}$ \\
\hline DMS. & 2,08 & 1,18 & 1,36 & 1,26 & 1,18 & 1,09 \\
\hline
\end{tabular}

ns, * - Não significativo e significativo a $5 \%$ de probabilidade, respectivamente.

Vałores, na coluna, seguidos pela mesma letra, não diferem entre si, estatisticamente, ao nivel de $5 \%$ de probabilidade.

\subsection{Composição gasosa no interior das embalagens}

As alterações gasosas ocorridas no interior das embalagens plásticas D-955 e PD-941, foram monitoradas durante o armazenamento frigorífico, cujos resultados encontram-se na figura 7 e Tabela 8.

O filme plástico PP PERF. apresentou, durante o período do monitoramento, uma composição gasosa semelhante a da atmosfera onde estava armazenado ( $21 \%$ de $\mathrm{O}_{2}$ e $0,03 \%$ de $\mathrm{CO}_{2}$, aproximadamente).

Os filmes plásticos D-955 e PD-941, tiveram uma variação intensa na concentração de $\mathrm{O}_{2}$ e $\mathrm{CO}_{2}$ até os 4 dias do armazenamento, com uma alta redução do $\mathrm{O}_{2}$ e acúmulo do $\mathrm{CO}_{2}$, devido a barreira parcial proporcionada pela embalagem à difusão dos gases, impedindo, até um certo limite, a reposição do $\mathrm{O}_{2}$ fixado e a saída do $\mathrm{CO}_{2}$ liberado no processo de respiração dos frutos. Concomitantemente observa-se uma elevação da concentração de etileno, o que está relacionado com o aumento do metabolismo respiratório e liberação 
do etileno endógeno dos frutos, resultando em acúmulo deste hormônio no interior da embalagem. O etileno sofre uma queda acentuada a partir do $4^{\circ}$ dia, coincidindo com o observado por Kader et al. (1989), quando relatou que sob condições atmosféricas modificadas a produção de etileno tende a diminuir.

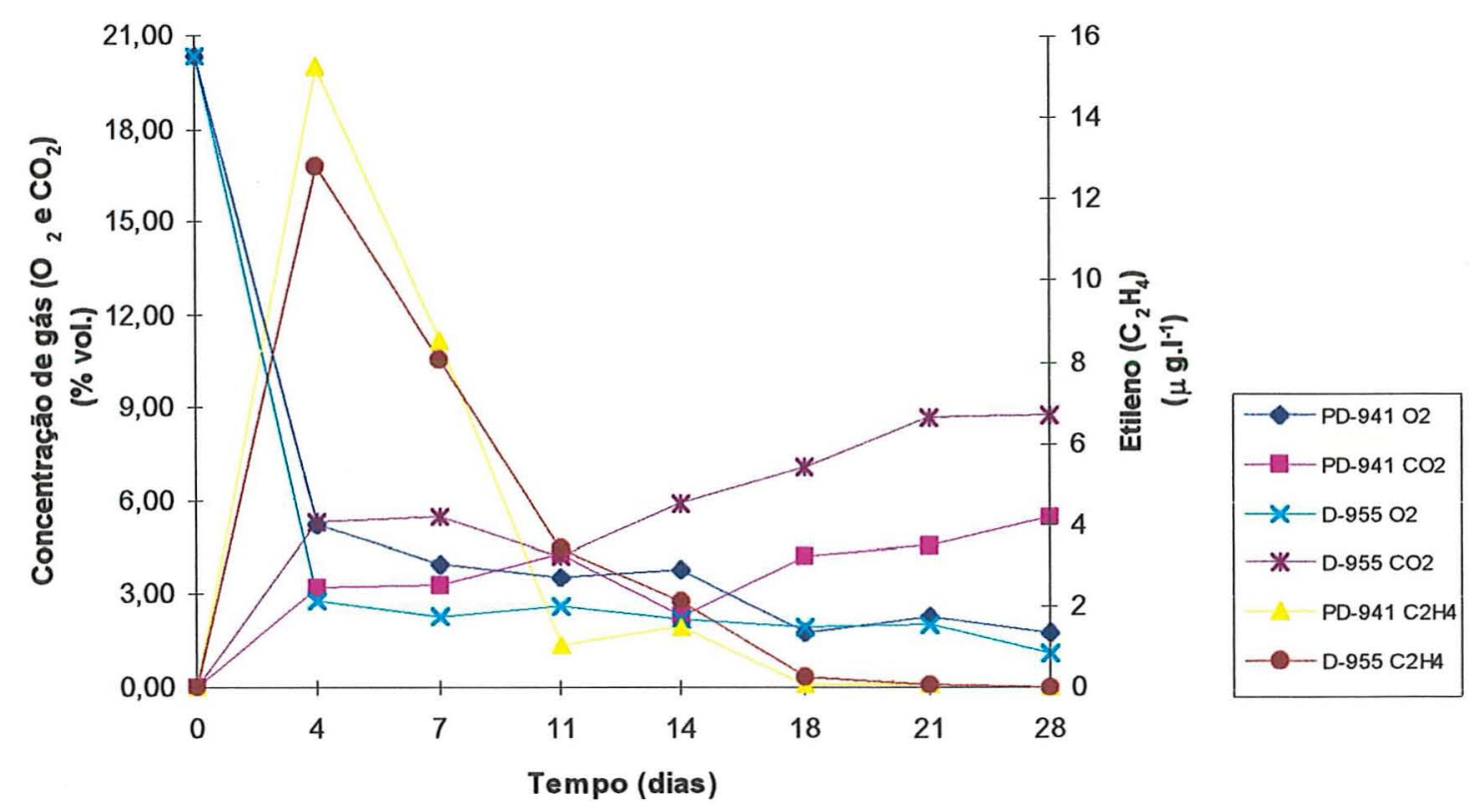

Figura 7. Composição gasosa $\left(\mathrm{O}_{2}, \mathrm{CO}_{2}\right.$ e $\left.\mathrm{C}_{2} \mathrm{H}_{4}\right)$ no interior das embalagens, durante armazenamento da manga 'Palmer' por 28 dias a temperatura constante de $12^{\circ} \mathrm{C}$.

Após os 4 dias de armazenamento, a taxa de $\mathrm{O}_{2}$ variou de 5,22 a $1,77 \%$ e a de $\mathrm{CO}_{2}$ de 3,25 a $5,46 \%$ no interior da embalagem plástica PD-941. No filme plástico D-955, a composição gasosa foi de 2,81 a 1,07\% de $\mathrm{O}_{2}$ e de 5,32 a $8,74 \%$ de $\mathrm{CO}_{2}$ no interior da embalagem, o que demonstra que a taxa de permeabilidade aos gases foi maior no filme plástico PD-941. 
Tabela 8. Composição gasosa $\left(\mathrm{O}_{2}, \mathrm{CO}_{2}\right.$ e $\left.\mathrm{C}_{2} \mathrm{H}_{4}\right)$ no interior das embalagens, durante armazenamento da manga 'Palmer' por 28 dias a temperatura constante de $12^{\circ} \mathrm{C}$.

\begin{tabular}{ccccccc}
\hline \multirow{2}{*}{$\begin{array}{c}\text { Tempo } \\
\text { (dias) }\end{array}$} & \multicolumn{3}{c}{$\mathrm{PD}-941$} & & \multicolumn{3}{c}{$\mathrm{D}-955$} \\
\cline { 2 - 3 } & $\mathrm{O}_{2}$ & $\mathrm{CO}_{2}$ & $\mathrm{C}_{2} \mathrm{H}_{4}$ & $\mathrm{O}_{2}$ & $\mathrm{CO}_{2}$ & $\mathrm{C}_{2} \mathrm{H}_{4}$ \\
\hline 0 & 20,32 & 0 & 0 & 20,32 & 0 & 0 \\
4 & 5,22 & 3,25 & 15,20 & 2,81 & 5,32 & 12,80 \\
7 & 3,96 & 3,33 & 8,50 & 2,31 & 5,50 & 8,05 \\
11 & 3,52 & 4,28 & 1,05 & 2,65 & 4,20 & 3,40 \\
14 & 3,78 & 2,32 & 1,50 & 2,18 & 5,92 & 2,15 \\
18 & 1,79 & 4,24 & 0,04 & 1,92 & 7,07 & 0,25 \\
21 & 2,24 & 4,59 & 0,04 & 2,06 & 8,70 & 0,08 \\
28 & 1,77 & 5,46 & 0 & 1,07 & 8,74 & 0 \\
\hline
\end{tabular}

Yamashita (1995), encontrou para o filme D-955 taxas que mantiveram-se em torno de 0,5 a $1 \%$ de $\mathrm{CO}_{2}$ e 19 a $21 \%$ de $\mathrm{O}_{2}$, em mangas 'Keitt' armazenadas durante 34 dias a $12^{\circ} \mathrm{C}$, no entanto, os frutos foram embalados individualmente.

Os frutos submetidos ao tratamento D-955, apresentaram um ligeiro sabor fermentado, no resultado da análise sensorial realizada aos 28 dias de armazenamento a $12^{\circ} \mathrm{C}$ e 6 dias (34 dias) a $25^{\circ} \mathrm{C}$, indicando que a atmosfera de 1,07 de $\mathrm{O}_{2}$ e $8,74 \%$ de $\mathrm{CO}_{2}$, foi suficiente para desencadear 0 processo de respiração anaeróbica, se refletindo em uma menor evolução da cor da casca e redução no teor de sólidos solúveis, confirmando o observado por Zagory \& Kader (1989) e Kader et al. (1989). Segundo Kader et al. (1989), uma taxa de $\mathrm{CO}_{2}$ acima de $5 \%$ seria suficiente para proporcionar uma mudança da respiração aeróbica para anaeróbica. 


\section{CONCLUSÕES}

O uso de ceras e filmes plásticos não tiveram influência sobre a vida útil dos frutos.

Os frutos tratados com filmes plásticos adquiriram sabor fermentado.

Os filmes plásticos PD-941 e D-955 retardaram o desenvolvimento dos sólidos solúveis dos frutos, embora isso não tenha refletido no aumento da sua vida útil.

O filme plástico PP PERF. não alterou as características de qualidade dos frutos.

A composição gasosa no interior da embalagem plástica PD941 , se mostrou mais adequada que a D-955.

Os frutos submetidos ao filme plástico D-955 não desenvolveram a cor da casca normalmente.

Os tratamentos com proteção de cera $1: 1$, com finalidade de conservar os frutos, não foram efetivos.

O tratamento REC. 1:1 não foi efetivo na manutenção das características dos frutos. 


\section{REFERÊNCIAS BIBLIOGRÁFICAS}

AKAMINE, E.K. Haden mango storage. Hawaii Farm Science, v. 12, n. 4, p. 6-7, 1963.

ASSOCIATION OF OFFICIAL ANALYTICAL CHEMISTS. Official methods of analysis of the association of official analytical chemists. 13. ed. Washington: AOAC, 1980. cap. 22, p. 359-73: Fruits and fruits products.

AVELAR FILHO, J.A. Estudo da conservação pós-colheita da mandioquinhasalsa (Arracacia xanthorriza Brancoft). Viçosa, 1989. 42p. Dissertação (M.S.) - Universidade Federal de Viçosa.

AWAD, M. Fisiologia pós-colheita de frutos. São Paulo: Nobel, 1993. 114p.

BAQUI, S.M.; MATTOO, A.K.; MODI, V.V. Mitochondrial enzymes in mango fruit during ripening. Phytochemistry, v. 13, p. 2049-55, 1974.

BEN-YEHOSHUA, S. Individual seal-packaging of fruit and vegetable in plastic film, new postharvest technique. HortScience, v. 20, p. 32-7, 1985.

BHATNAGAR, H.C.; SUBRAMANYAM, H. Some aspects of preservation, processing and export of mangos and its products. Indian Food Packer, v. 27, n. 4, p. 33-52, July/Aug. 1973. 
BLEINROTH, E.W. Armazenamento de frutos e hortaliças II. Fundamentos teóricos da conservação pelo frio das frutas e hortaliças. Boletim do ITAL, n. 34, p. 35-53, jun. 1973.

BLEINROTH, E.W. Matéria prima. In: MEDINA, J.C.; BLEINROTH, E.W.; MARIN, Z.J. de. et al. Manga: da cultura ao processamento e comercialização. Campinas: ITAL, 1981. p. 243-92. (Frutas Tropicais, 8).

BLEINROTH, E.W. Manuseio e tratamento de pós-colheita da manga. In: SIMPÓSIO BRASILEIRO SOBRE MANGICULTURA, 2., Jaboticabal, 1989. Anais. Jaboticabal: UNESP/FCAVJ, 1989. p. 171-84.

BOSE, A.N.; BASU, G. Studies on the use of coating for extension of storage life on fresh Fajli mango. Food Research, v. 19, p. 424-8, 1954.

CAMILLO-LÓPEZ, A.; ROJAS-VILLEGAS, R.; VALDEZ TORRES, J.B.; YAHIA, E.M. Ripening and quality of mango fruit as affected by coating with "Semperfresh". Acta Horticulturae, v. 370, p. 203-16, 1995.

CAMPBELL, J.R. Commercial Florida mango cultivars. Acta Horticulturae, v. 341, p. 55-9, 1993.

CASTRILLO, M.; BERMUDEZ, A. Post-harvest ripening in wax coated bocado mango. International Journal of Food Science and Technology, v. 27, n. 4, p. 457-63, 1992.

CHATPER, H.S.; GEETHA, G.; MATOO, A.K. et al. Some problems pertaining to storage and ripening in mango fruit. Acta Horticulturae, v. 24, p. 243$50,1972$. 
CHEEMA, G.S.; KARMAKAR, D.V.; JOCHI, B.M. Investigation of the cold storage mangoes. Indian Journal of Agricultural Sciences, v. 20, n. 3, p. 259-325, 1950.

CHITARRA, M.I.F.; CHITARRA, A.B. Pós-colheita de frutos e hortaliças: fisiologia e manuseio. Lavras: ESAL/FAEPE, 1990. 320p.

COELHO, A.H.R. Qualidade pós-colheita de pêssegos. Informe Agropecuário, v. 17, n. 180, p. 31-8, 1994.

DHARKAR, S.D.; SAVAGAON, K.A.; SRIRANGARAJAN, A.N. et al.. Irradiation of mangoes. II. Radiation effects of skin-coated Alphonso mangoes. Journal of Food Science, v. 31, p. 870-7, 1966.

DONADIO, L.C.; SOARES, N.B.; MORAES, L.G. et al. Características de algumas variedades de mangueira cultivadas no Estado de São Paulo. Campinas: CATI, 1982. 16p. (Boletim Técnico da CATI, 171).

FAO PRODUCTION YEARBOOK - 1994, v. 48, p. 164-5, 1995.

HAINES, W. The world mango situation - a market perspective. Acta Horticulturae, v. 291, p. 1-11, 1991.

HAKNESS, R.W.; CORBIN, M. Haden mango maturity observation during 1950. Proceedings of the Florida Mango Forum, v. 10, p. 27-32, 1950.

HARMAN, J.; WATKINS, C. Use of the refractometer to estimate the soluble solids of fresh fruits. The Orchardist of New Zealand, v. 54, n. 1, p. 35-7, Feb. 1981. 
HATTON, T.T.; REEDER, W.F. Controlled atmosphere storage of Keitt Mango. Proceedings of the American Society of Horticultural Science, v. 10, p. 114-21, 1965.

HOFFMAN, N.E.; YANG, S.F. Changes of 1-aminocyclopropane-1-caboxylic acid content in ripening fruits in relation to their ethylene production rates. Journal of the American Society of Horticultural Science, v. 105, p. $492-$ $5,1980$.

HUDDAR, A.G.; BHARALI, B.C.; THIMA RAJU, K.R. Note on extension of storage of mango fruits by Tal-prolong. Acta Horticulturae, v. 231, n. 2, p. 668-9, 1988.

JAGDISH-CHANDRA; PATHAK, V.N.; CHANDRA, J. Effect of plastic REC wrapping on post-harvest fungal rot of mango fruit. Indian Phytopatology, v. 45, n. 1, p. $126-7,1992$.

JAUHARI, O.S.; TRIPATHI, K.S. Studies in maturity standards for Mangifera indica L. var. "Bombain Yellow". Acta Horticulturae, v. 24, p. 271-5, Mar. 1972.

KADER, A.A. Modified atmospheres and low-pressure systems during transport and storage. In: KADER, A.A.; KASMIRE, R.F.; MITCHELL, F.G. et al. Postharvest Technology of Horticultural Crops. Oakland: University of California, 1985. cap. 11, p.58-64. 
KADER, A.A.; ZAGORY, D.; KERBEL, E.L. Modified atmosphere packaging of fruits and vegetable. Critical Reviews in Food Science and Nutrition, v. 28, n. 1, p. 1-30, 1989.

KALRA, S.K.; TANDON, D.K. Ripening behaviour of "Dashehari" mango in relation to harvest period. Scientia Horticulturae, v. 19, p. 263-9, 1983.

KAPSE, B.M.; RANE, D.A.; KHEDKAR, D.M. Correlation between bio-chemical parameters and organoleptic evaluation in mango varieties. Acta Horticulturae, v. 231, n. 2, p. 756-62, 1988.

KLUGE, R.A.; JORGE, R.O. Efeito da embalagem de polietileno na frigoconservação de ameixas "Amarelinhas". Revista Brasileira de Fruticultura, v. 14, n. 3, p. 21-5, 1992.

KRISHNAMURTHY, S. Effects of Tal-prolong on shelf-life and quality attributes of mango. Acta Horticulturae, v. 231, n. 2, p. 668-9, 1988.

KRISHNAMURTHY, S.; JOSHI, S.S. Studies on low temperature storage of Alphonso mango. Journal of Food Science and Technology v. 26, n. 4, p. $177-80,1989$.

KRISHNAMURTHY, S.; SUBRAMANYAM, H. Pre and postharvest physiology of the mango fruit (Mangifera indica L.). Tropical Science, v. 15, n. 2, p. 167-93, 1973.

LAM, P.F.; NG, K.H.; OMAR, D. Physical, physiological and chemical changes of Galek after harvest. In: WORKSHOP ON MANGO AND RAMBUTAM, Laguna, 1982. / Resumo em Agris, 1981-85/. 
LELEY, D.K.; NARAYANA, M.; DAJI, I.A. Biochemical studies in growth and ripening of the Alfonso mango. Indian Journal of Agricultural Sciences, v. 13, p. 291-9, 1943.

LIZADA, M.C.C.; SJAIFULLAH AJILLON, A.B.: VALDEZ, E.R. 1aminocyclopropane-1-carboxylic acid in tropical fruits and vegetables. Acta Horticulturae, v. 138, p. 329-36, 1983.

MEDINA, J.C.; BLEINROTH, E.W.; MARIN, Z.J. de. et al. Manga: da cultura ao processamento e comercialização. Campinas: ITAL, 1981. 399p. (Frutas Tropicais, 8).

MEDLICOTT, A.P. Mango fruit ripening and the effects of maturity, temperature and gases. Wolverhampton, 1985. 194p. Thesis (Doctor) - University of Wolverhampton.

MEDLICOTT, A.P.; JEGER, M.J. The development and application of postharvest handling treatments to manipulate ripening in mangoes. In: PRINSLEY, R.T.; TUCKER, R.T., ed. Mangoes: a review. London: Commonwealth Science Council, 1987. p. 56-77.

MEDLICOTT, A.P.; BHOGAL, M.; REYNOLDS, S.B. Changes in peel pigmentation during ripening of mango fruit (Mangifera indica var. Tommy Atkins). Annals of Applied Biology, v. 109, p. 651-6, 1986. 
MEDLICOTT, A.P.; N'DAIYE; SIGRIST, J.M.M. Harvest maturity and concentration and exposure time to acetylene influence initiation of ripening in mangos. Journal of the American Society for Horticultural Science, v. 115, n. 3, p. $426-30,1990$ a.

MEDLICOTT, A.P.; SIGRIST, J.M.M.; SY, O. Ripening of mangos following lowtemperature storage. Journal of the American Society for Horticultural Science, v. 115, n. 3, p. $430-4,1990$ b.

MEDLICOTT, A.P; REYNOLDS, S.B.; NEW, S.W. et al. Harvest maturity effects on mango fruit ripening. Tropical Agriculture, v. 65, n. 2, p. 153-7, Apr. 1988.

MEDLICOTT, A.P.; SIGRIST, J.M.M.; REYNOLDS, S.B. et al. Effects of ethylene and acetylene on mango fruit ripening. Annals of Applied Biology, v. 111, p. 439-44, 1987.

MILLER, W.R.; HALE, P.W.; SPALDING, D.H. et al. Quality and decay of mango fruit wrapped in heat-shrinkable film. HortScience, v. 18, n. 6, p. 957-8, 1983.

MORGA, N.S.; LUSTREE, A.O.; TUNAC, M.M. et al. Physic-chemical change in Philippine Carabao mangoes during ripening. Food Chemistry, v. 4, p. 225-34, 1979.

O'HARE, T.J.; PRASAD, A. The effect of temperature and carbon dioxide on chilling symptoms in mango. Acta Horticulturae, v. 343, p. 244-50, 1993. 
ORTIZ, S.A. Prevenção a perdas e estragos através de embalagens adequadas para produtos hortigranjeiros. In: CONGRESSO BRASILEIRO DE EMBALAGENS, 2., São Paulo, 1980. Anais. São Paulo: s. ed., 1980. p. 56-60.

PADULA, M.; SARANTÓPOULOS, C.I.G.L.; ARDITO, E.F.G. et al. Embalagens plásticas: controle de qualidade. Campinas: ITAL/SBCTA, 1989. 202p.

PANTASTICO, E.B., ed. Postharvest physiology, handling and utilization of tropical and subtropical fruits and vegetables. Laguna: The AVI Publishing, 1975. 560p.

PANTASTICO, E.B.; LAM; P.F.; KETSA, S. et al. Postharvest physiology and storage of mango. In: MENDONZA JR.; D.B.; WILLS, R.B.H, ed. Mango fruit development, postharvest physiology and marketing in ASEAN. Koala Lampur: Asean Food Handling Bureau, 1984. p. 39-52.

PARMAR, P.B.; CHUNDAWAT, B.S. Effect of various post-harvest treatments on the physiology of Kesar mango. Acta Horticulturae, v. 231, n. 2, p. 679-84, 1988.

PEARSON, D. Laboratory techniques in food analysis. London: Butterworths, 1973. cap. 2, p. 27-77: General methods - basic constituintes/sugar. 
PREGNOLATTO, W.; PREGNOLATTO, N.P., coord. Normas analíticas do Instituto Adolfo Lutz. 3. ed. São Paulo: Instituto Adolfo Lutz, 1985. v. 1: Métodos químicos e físicos para análise de alimentos, cap. 4, p. 16-76: Determinações gerais.

RAMOS, V.H.V. Conservação pós-colheita de manga por meio do tratamento químico, da embalagem plástica e da cera associados à hidrotermia e refrigeração. Jaboticabal, 1994. 179p. Tese (Doutorado) - Faculdade de Ciências Agrárias e Veterinárias de Jaboticabal, Universidade Estadual Paulista, "Júlio de Mesquita Filho".

RAO, P.V.S.; GIRIDHAR, N.; PRASAD, P.S.K. et al. Optimum maturity and harvesting time mangoes var. Beresham, and physico-chemical components of fruit maturity. Indian Journal of Horticultural Science., $v$. 29, n. 2 , p. $126-34,1972$.

REID, M.S. Product maturation and maturity indices. In: KADER, A.A.; KASMIRE, R.F.; MITCHELL, F.G. et al. Postharvest Technology of Horticultural Crops. 2.ed. Oakland: University of California, 1985. cap. 3, p. 8-11.

ROE, B.; BRUEMMER, J.H. Changes in pectin substances and enzymes during ripening and storage of "Keitt" mangoes. Journal of Food Science, v. 46, n. 1, p. 186-9, 1981.

SAMSON, J.A. Tropical fruits. 2. ed. London: Longmam Scientific \& Technical, 1989. cap. 8, p. 216-34: Mango. 
SÃO JOSÉ, A.R.; SOUZA, I.V.B. Manga: produção e comercialização. Vitória da Conquista: DFZJUESB, 1992. 110p.

SAS INSTITUTE INC. SAS ${ }^{\circledast}$ User's guide: statistics. 5. ed. Cary, 1985. 956 p.

SEYMOUR, G.B.; N'DIAYE, M.; WAINWRIGHT, H. et al. Effects of cultivar and harvest maturity on ripening of mangoes during storage. Journal of Horticultural Science, v. 65, n. 4, p. 479-83, 1990.

SHARMA, G.D.; KAPUR, N.S. Role of skin coating on the transportation of perishables. IV. Studies on the transportation of mangoes. Indian Food Packer, v. 21, p. 34-6, 1967.

SHEWFELT, R.L. Postharvest treatment for extending the shelf life of fruits and vegetable. Food Technology, p. 8-12, May 1986.

SHEWFELT, R.L. Meassuring quality and maturity. In: SHEWFELT, R.L.; PRUSSIA, S.E., ed. Postharvest handling: a systems approach. London: Academic Press, 1993. cap. 5, p. 100-19.

SHIVARANA-REDDY, L.; THIMMA RAJU, K.R. Effects of pre-packaging and post-harvest treatments on storage behavior of mango fruits cv. Alphonso. Acta Horticulturae, v. 231, n. 2, p. 670-4, 1988.

SILVA, B.P. da. Exportações brasileiras de frutas frescas. Informe Agropecuário, v. 17, n. 179, p. 5-7, 1994. 
SORNSRIVICHAI, J.; ANUSADORN, P.; OOGAKI, C. et al. Storage life and quality of mango (Mangifera indica L. CV. Keaw Savoey) fruits stored in sealpackaging by plastic film and under low pressure at different temperatures. Japanese Journal of Tropical Agriculture , v. 33, n. 1, p. 5-17, 1989.

STAFFORD, A.E. Mango. In: CHAN JR., H.T., ed. Handbook of Tropical Foods. New York: Marcel Dekker, 1983. p. 399-431.

SUBRAMANYAM, H.; KRISHNAMURTHY, S.; PARDIA, H.A.B. Physiology and biochemistry of mango fruit. Advances in Food Research, v. 21, p. 223305, 1975.

SUNDARARAJ, J.S.; MUTHUSWAMY, S; SADASIVAM, R. Storage of mango fruits. Acta Horticulturae, v. 24, p. 265-70, Mar. 1972.

THOMAS, P.; OKE, M.S. Improvement in quality and storage of 'Alphonso' mangoes by cold adaptation. Scientia Horticulturae, v. 19, p. 257-62, 1983.

THOMPSON, A.K. The storage of mango fruits. Tropical Agriculture, v. $48, n$. 2, p. 63-9, Jan. 1971.

VASQUEZ-SALINAS, C.; LAKSHMINARAYANA, S. Compositional changes in mango fruit during ripening at different storage temperatures. Journal of Food Science, v. 50, p. 1646-8, 1985.

WANG, C.Y. Approaches to reduce chilling injury of fruits and vegetables. Review Horticultural, v. 15, p. 84-5, 1995. 
YAMASHITA, F. Armazenagem frigorifica de mangas (Mangifera indica L. cV. Keitt) embaladas sob atmosfera modificada. Campinas, 1995. $1 \mathrm{v}$. Tese (Doutorado) - Faculdade de Engenharia de Alimentos, Universidade Estadual de Campinas.

YUEN, C.M.C.; TAN, S.C.; JOYCE, D. et al. Effect postharvest calcium and polymeric films on ripening and peel injury in Kensington Pride mango. ASEAN Food Journal, v. 8, n. 3, p. 110-3, 1993.

YUNIARTI, K.; SUHARDI, R. Ripening retardation of Arumanis mango. ASEAN Food Journal, v. 7, n. 4, p. 207-8, 1992.

ZAGORY, D.; KADER, A.A. Quality maintenance in fresh fruits and vegetables by controlled atmospheres. In: JEN, J.J. Quality factors of fruits and vegetable : chemistry and technology. Washington: American Chemical Society, 1989. cap. 14, p. 174-88. 
APÊNDICE 
Ficha de avaliação sensorial da manga

Nome:

Data:

Por favor, avalie as amostras de manga quanto a odor, sabor e qualidade global, seguindo as escalas abaixo:

\begin{tabular}{|l|l|}
\hline ODOR E SABOR & QUALIDADE GLOBAL \\
\hline 1. Ausente & 9. Gostei muitissimo \\
\hline 2 & 8. Gostei muito \\
\hline 3. Ligeiro & 7. Gostei moderadamente \\
\hline 4 & 6. Gostei ligeiramente \\
\hline 5. Moderado & 5. Indiferente \\
\hline 6 & 4. Desgostei ligeiramente \\
\hline 7. Forte & 3. Desgostei moderadamente \\
\hline 8 & 2. Desgostei muito \\
\hline 9. Extremamente forte & 1. Desgostei muitissimo \\
\hline
\end{tabular}

\begin{tabular}{ccccccc}
\hline \multirow{2}{*}{$\begin{array}{c}N^{\circ} \text { da } \\
\text { amostra }\end{array}$} & \multicolumn{2}{c}{ ODOR } & \multicolumn{3}{c}{ SABOR } & QUALIDADE \\
\cline { 2 - 3 } & Caract. & Estranho & $\begin{array}{c}\text { Caract. } \\
\text { (doce) }\end{array}$ & Fermentado & Acido & GLOBAL \\
\hline
\end{tabular}

Obs: 